\title{
Means of Payment and Timing of Mergers and ACquisitions in a Dynamic Economy*
}

\author{
Alexander S. Gorbenko \\ London Business School
}

\author{
Andrey Malenko \\ MIT Sloan School of Management
}

This version: February 2013

\footnotetext{
${ }^{*}$ We are grateful to Peter DeMarzo, Michael Fishman, Julian Franks, Richmond Mathews (WFA discussant), Matthew Rhodes-Kropf, Andrzej Skrzypacz, seminar participants at London Business School, Kellogg School of Management, and participants at the NES 20th Anniversary Conference and the 2011 WFA meeting (Santa Fe) for helpful comments. Address for correspondence: Gorbenko: London Business School, Regent's Park, London, NW1 4SA, UK, agorbenko@london.edu; Malenko: MIT Sloan School of Management, 100 Main Street, E62-619, Cambridge, MA 02142, USA, amalenko@mit.edu.
} 


\title{
Means of Payment and Timing of Mergers And ACQUISITIONS IN A DYNAMIC ECONOMY
}

\begin{abstract}
This paper studies the interaction between takeover activity, means of payment (cash versus stock), and premiums in a dynamic realoptions model. The timing of takeovers and the equilibrium bids in contests with multiple bidders are driven by three factors: synergies of the bidder with the target, cash constraints of the bidder, and cash constraints of its competitors. The model produces many testable hypotheses, both novel and consistent with existing studies. First, contests in stock extract more surplus from the bidder, so highersynergy bidders benefit from approaching targets when they are smaller and acquiring them in cash. This self-selection by bidder quality can explain higher takeover premiums in cash versus stock deals in the sample of takeovers. Second, cash constraints need not have a monotonic effect on incentives of bidders to approach the target. Finally, high deal activity can be caused by shocks not only to valuations but also to cash constraints.
\end{abstract}

Keywords: Auctions, financial constraints, cash constraints, mergers and acquisitions, real options, security design. 
The decision to merge is clearly one of the most important choices that the firm's management and board of directors face, with the potential to gain or lose millions and billions in profit. ${ }^{1}$ It is therefore important to understand how these multifaceted decisions are made, what factors affect them. Among the most important choices in mergers are timing and the medium of exchange: a bidder must decide when to approach the target with an offer and which form of payment to use. These choices are affected by various firm-specific and economy-wide changes. In particular, it is known that mergers often occur in waves that are correlated with periods of economic expansion and easy access to external financial markets, or financing constraints. ${ }^{2}$ In this paper, we provide a theoretical analysis of mergers based on two simple ideas: (i) a bidder can choose when to approach the target with an offer; (ii) his ability to pay cash is limited by a financing constraint. We show that a simple real options model of mergers has the potential to match much of the empirical evidence on the relation of merger activity to economic shocks, financing constraints, medium of exchange of the offers, and the distribution of gains among the contest participants. In addition, we provide a few novel predictions that relate to this interdependence.

More specifically, we consider a dynamic model in which there are three agents: a target and two potential bidders. The target is a growth firm: her assets and cash flows grow over time with some uncertainty. Both bidders are mature companies: their assets and cash flows do not grow without acquiring the target. ${ }^{3}$ The bidders have synergies with the target: an acquisition improves productivity of the target in a combined company by a bidder-specific multiple. At any time each bidder can approach the target with an offer. Once a bidder makes a bid, the auction between the first bidder and the competitor is initiated, and the bidder who submits the highest bid wins the contest. A bidder's decision when to approach the target reflects the following trade-off. On one hand, approaching the target early leads to an earlier increase in her productivity; on the other hand, a deal involves a cost: the post-merger market share of the losing bidder diminishes. If the synergy parameter of a bidder is small, it is optimal to wait until the target grows in size so that the increase in her productivity outweighs the cost of acquisition.

The second building block of the model is information asymmetry between the target and the

\footnotetext{
${ }^{1}$ In 2007 alone, the value in dollars of world-wide deal volume exceeded $\$ 4.8$ trillion.

${ }^{2}$ For evidence on procyclicality of mergers see Mitchell and Mulherin (1996) and Maksimovic and Phillips (2001). For evidence on relation of mergers to the costs of borrowing see Harford (2005).

${ }^{3}$ An alternative interpretation of the framework is that the target's assets and cash flows change relative to those of the bidders.
} 
bidders. Similarly to the literature that studies takeovers as auctions but unlike the prior literature that considers takeovers in the real options framework, we assume that potential synergies from acquiring the target is the private information of the bidder. As shown in the literature on securities auctions, this feature makes bids in stock and in cash not equivalent, in contrast to the case when bidders do not have any private information. Specifically, because the value of a bid in stock (but not in cash) depends on the bidder's private information, in a stock auction, it is more costly for a bidder to separate himself from a marginally lower type. Even if both bidders offer the same proportion of the combined company, the bidder with the higher valuation will end up paying more. Because of this effect, which is a version of the linkage effect (Milgrom and Weber, 1982), each bidder wants to bid in cash whenever possible. The ability to do this is, however, limited by imperfect access of the bidder to the financial market: he cannot pay in cash above a certain limit.

We initially solve for the equilibrium initiation strategies and terms of takeovers when means of payments are exogenous: both bidders submit bids in cash; in stock; or one bidder submits bids in cash and the other in stock. These cases correspond to special cases of the general model, in which financing constraints of each bidder are either infinite or zero. Then, we provide solution of the general model with arbitrary cash constraints. The model delivers a number of implications relating timing of mergers, synergies, and means of payments.

We show that high-synergy targets are typically acquired young and with cash, while low-synergy targets are typically acquired old (if at all, despite positive synergies) and with stock. Intuitively, if the target is high-synergy, it does not pay off to wait and the target is acquired when small. As a result, for an acquirer, the required payment is likely to be below the financing constraint, leading to deals done in cash. Because of high synergies, such deals are also likely to result in high takeover premiums (relative to the current value of the target under her current management). Thus, the model predicts that in a sample of deals, cash deals can be associated with higher takeover premiums, despite stock deals being perceived as more expensive by bidders. This finding is broadly consistent with empirical evidence (e.g., Betton, Eckbo, and Thorburn, 2008). While this evidence can seem inconsistent with predictions of security-bid auctions literature, it becomes consistent once dynamic self-selection of targets by bidders into cash and stock deals is taken into account.

The model delivers interesting comparative statics as to what deals are likely to be done in cash versus in stock and when. For example, all else equal, the option to delay approaching the target is higher if the value of the target's assets is more volatile. Thus, such targets are acquired later, when the financial constraint of the acquirer is less likely to be satisfied, and hence, are more likely to occur 
in stock. All else equal, stock deals for these targets are also, on average, better than stock deals for lower-risk targets: they have higher average synergies and higher average takeover premiums.

Surprisingly, the financing constraint of a bidder need not have a monotonic effect on her initiation strategy. There are two effects in play. On one hand, if the financing constraint of a bidder is only slightly relaxed, he is able to finance best deals with cash if they are sufficiently small, which leads to his higher surplus and consequently to an earlier optimal initiation. On the other hand, if the bidder is already able to do most deals in cash, he is less under pressure to "fit into" cash: further relaxing the constraint gives him the ability to postpone the deal without incurring the cost of a stock deal. If the two bidders have asymmetric financing constraints, their initiation strategies are asymmetric as well. Thus, conditional on the contest being initiated, participating bidders with different constraints can have asymmetric distributions of synergies even if those are symmetric ex ante. In equilibrium, the initiating bidder does not always win. Consistent with empirical evidence (Betton, Eckbo, and Thorburn (2009)), for some parameters of the model contests initiated in cash are less often rejected in favor of a competing bid due to the link between synergies and the resulting means of payment: contests are usually completed in cash by the strongest acquirers against the weakest competitors.

Taken together, our results suggest that the decision to initiate a takeover contest is driven by three fundamental factors: the technological shocks that affect the state process of the synergies from the acquisition, the cash constraints of the bidder, and the bidder's perception of the cash constraints of other potential bidders. While the importance of technology shocks has often been acknowledged in the prior literature (e.g., Mitchell and Mulherin, 1996, Jovanovic and Rousseau, 2002, Lambrecht, 2004), the effect of cash constraints is more subtle. Indeed, a naive argument suggests that in a dynamic setting, the presence of cash constraints should either accelerate or have no effect on the decision to acquire. The logic is as follows. First, if a bidder is cash constrained, his only chance to acquire the target is when she is relatively small, which could be a suboptimal decision for an unconstrained bidder. Second, if a constrained bidder can use stock, he can simply offer the target the proportion of the stock of the combined firm that is equal in value to his potential cash bid. We show that the naive argument is not valid when the bidders have privately known synergies. In this case, cash constraints can significantly delay mergers, consistent with the findings of Harford (2005).

Our paper is related to two strands of research. First, it is related to the literature that studies the role of means of payment in mergers and acquisitions and, more generally, in auctions, in which bidders can make bids in securities. ${ }^{4}$ Many of our empirical implications on stock versus cash payments in

\footnotetext{
${ }^{4}$ Some real estate sales and long-term lease offerings attract competitive bids and result in a buyer paying an equivalent
} 
mergers are also delivered in Fishman (1989) via a different mechanism. Fishman (1989) provides a static model of means of payments that features a two-sided information asymmetry between bidders and the target. ${ }^{5}$ The advantage of a stock bid is that it reduces the adverse selection problem, inducing a more efficient accept/reject decision of the target. A cash bid is, however, used when a bidder has a high enough valuation to preempt competition by signaling a high valuation. In contrast to Fishman (1989), our paper shows that a one-sided information asymmetry in which only bidders have private information is sufficient to capture empirical evidence on means of payments, once dynamic aspects are taken into account. It also explains why stock bids are often perceived as more expensive by bidders but look smaller in the data. Clearly, both stories manifest in the data. The way to test the relative importance of the two explanations for the observed means of payments would be to account for the timing of acquisitions, such as size of the target and its age, and financing constraints of bidders. More generally, our paper is related to the literature on security-bid auctions (Hansen, 1985; Rhodes-Kropf and Viswanathan, 2000, and DeMarzo, Kremer, and Skrzypacz ,2005).

Second, our paper is related to the literature that studies mergers as real options. Lambrecht (2004) provides a setting in which mergers are driven by economies of scale and shows that the merger takes place once the price of the industry output raises to a sufficiently high threshold, thereby providing a rationale for the procyclicality of mergers. Morellec and Zhdanov (2005) build on the framework of Lambrecht to study mergers in a setting with incomplete information between the market and the merging firms. Hackbarth and Morellec (2008) apply a real options framework to analyze the dynamics of stock returns and risk in mergers and acquisitions. Versions of a real options framework have also been applied to study the effects of bidders' financial structure (Morellec and Zhdanov (2008)) and product market competition (Hackbarth and Miao (2012)). Our paper differs from the extant literature in one important aspect: while this literature assumes that all bidders and the target have perfect information about the gains from acquisition, we follow the traditional literature on auctions in assuming that bidders have private information about their synergies with the target. This assumption has a crucial effect on the role of means of payment in takeovers. If all bidders and the target have perfect information about the gains from the synergies, takeover battles in stock and in cash are equivalent, as discussed in Morellec and Zhdanov (2008): stock bids are not subject to the linkage effect, and thus there is no difference in the values of stock bids and cash bids. Because we of cash and securities (e.g., a fixed payment stream plus a claim on earnings). The choice of timing is also important in these deals.

${ }^{5}$ In addition to Fishman (1989), models of means of payments that are based on two-sided information asymmetry are provided by Hansen (1987), Eckbo, Giammarino, and Heinkel (1990), and Berkovitch and Narayanan (1990). 
allow for bidders' private information about their synergies, battles in cash and in stock are no longer equivalent, which allows us to discriminate between takeovers in cash and in stock.

The remainder of the paper is organized in the following way. Section I outlines the setup of the model. Section II solves the model with exogenous means of payments, or equivalently, special cases of the general model in which cash constraints are either perfect or non-existent. Section III solves the general model. Section IV provides the comparative statics analysis. Section V studies the properties of the equilibrium and the predictions of the model, and discusses testable hypotheses. Section VI concludes. All proofs appear in Appendix A. Appendix B contains the details of the numerical solution of the model.

\section{Model Setup}

We consider a setting in which the risk-neutral target attracts two potential risk-neutral acquirers, or bidders. The roles of the target and the bidders are exogenous. The value of the target as a separate entity at time $t$ is given by $X_{t}$, where $X_{t}$ evolves as a geometric Brownian motion:

$$
d X_{t}=\mu X_{t} d t+\sigma X_{t} d B_{t}, X_{0}=x .
$$

Here, $\mu$ and $\sigma>0$ are constant growth rate and volatility, and $d B_{t}$ is the increment of a standard Brownian motion. The discount rate is equal to $r>\mu$. Process $\left(X_{t}\right)_{t>0}$ is a reduced-form specification of the present value of the target's assets. For example, one obtains this value if the target firm produces cash flow $(r-\mu) X_{t}$ per unit of time. We interpret it as the current size of the target. It accounts for all exogenous shocks to their value, such as changes in the price of the final product and inputs, as well as for the endogenous response of the target firm to them. ${ }^{6}$ The initial value of each bidder as a separate entity is constant at $\Pi_{b}{ }^{7}$ If bidder $i$ acquires the target at time $t$, the value of the combined firm is

$$
\Pi_{b}+v_{i} X_{t}
$$

\footnotetext{
${ }^{6}$ In this paper, we focus on fundamental rather than market prices of the target (that is, prices clear of market expectations about the potential acquisition). This is consistent with related empirical studies, in which target prices are typically cleared of pre-acquisition runups.

${ }^{7}$ Bidders' values are equal for simplicity of exposition; this assumption does not affect the main trade-offs of the model. With different bidders' values, it is less clear how to compare values of their bids in securities. Section II.C provides a way to compare such bids in a different context.
} 
where $v_{i} \in[\underline{v}, \bar{v}], \bar{v}>\underline{v}>1$ is the multiple that characterizes an improvement in operations of the target due to a change in ownership from a stand-alone firm to bidder $i{ }^{8}$ We refer to $v_{i}$ as the synergy parameter. Importantly, each bidder's synergy with the target is the bidder's private information that is known to him before the start of the acquisition process. ${ }^{9}$ The target and the bidders share common knowledge about the distribution of synergies unknown to them: they are distributed with p.d.f. $f(v)>0$ on $[\underline{v}, \bar{v}]$. We assume that the distribution of valuations satisfies the restriction that the expected payoff of a winning bidder with valuation $v$ monotonically increases in $v$ in all specifications. ${ }^{10}$ To represent the potential change in the industry structure after the acquisition, we assume that the losing bidder is also affected by the acquisition: his value changes from $\Pi_{b}$ to $\Pi_{o}<\Pi_{b}$. The loss in the losing bidder's value will be a source of delay in the acquisition contests in the model. Of course, other potential sources of delay such as direct costs of initiating the takeover contest are possible too. We denote the value loss of the losing bidder as $\Delta \equiv P_{b}-P_{o}$.

The main goal of the paper is to study how initiation of takeovers interacts with the parameters of economic environment and the outcomes of the takeover contests. In practice, takeover contests are typically initiated when a potential bidder approaches the target's board with a formal or informal offer. To reflect this practice, we assume that each bidder has a real option to approach the target with a take-it-or-leave-it offer at any time. If a bidder approaches the target at time $t$, the takeover contest is initiated and both bidders compete for the target in an open ascending-bid (English) auction.

The term English auction refers to a wide variety of open ascending-bid auction formats, which can differ in their precise rules. The most convenient formalization of English auctions is the "button" auction introduced by Milgrom and Weber (1982). Initially, all bidders are active. An auctioneer sets the price at zero and gradually raises it. All bidders observe the current price and the number of still active bidders. A bidder confirms his participation continuously until the raising price forces him to withdraw from the auction. Aa soon as only one bidder remains, he is declared the winner and pays the current price.

Each bidder can submit bids in the form of cash or stock of the combined company, or any mixture of the two. ${ }^{11}$ Thus, in contrast to the static auction literature and natural to the dynamic setting of

\footnotetext{
${ }^{8}$ Allowing $\underline{v}$ below 1 does not add to the model intuition in any way. However, in the model, we show that even some bidders with $v>1$ will choose to never initiate the acquisition process.

${ }^{9}$ Introducing the additional private information that the bidder can learn at the beginning of the contest does not affect the results of the model qualitatively. It is only the ex-ante private information that defines bidders' strategies to initiate the takeover contest.

${ }^{10}$ For example, in the model of Section II.B this restriction is equivalent to a restriction that $v-\mathbb{E}[w \mid w \leq v]$ is a strictly increasing function of $v$. An example of distribution that satisfies these restrictions is uniform distribution.

${ }^{11}$ We generalize the "button" auction to the cases of stock and mixed bids in Sections II.B and II.C.
} 
our problem, each bidder needs to decide not only how much to bid, but also when to make an offer for the target. The assumption that bidders but not the target determine the timing of a takeover can be justified by the absence of commitment to sell on the part of the target. If the target announces that she wants to sell herself before any bidder is ready to make a move, the bidders can always delay the acquisition by not participating in the target-initiated process. On the other hand, when the bidder with positive value is ready to make an offer then, consistent with the "Revlon Duty," the target's board would be responsible to consider all offers and accept the highest bid offered provided that it exceeds the value of the target under the current management.

Because all private information about future synergies is on the side of the bidders, they have incentives to pay in cash whenever possible. ${ }^{12}$ In the prior literature on mergers and acquisitions, stock bids are rationalized using either adverse selection about the acquirer's assets in place or private information of the acquirer about his own firm. ${ }^{13}$ In this paper, we abstract from these issues and instead focus on another reason why bidders make bids in stock of the combined company - cash constraints of the bidder. Specifically, other things equal, a bidder wants to make a bid in cash because it is cheaper to separate from lower types in cash than in stock. However, the ability to submit bids in cash is limited, because the bidder's internal cash is finite and borrowing from the outside investors can be expensive for various reasons. For simplicity, we suppose that bidder $i$ has only $C_{i}$ units of cash, and the cash constraints are infinitely rigid after that: in other words, bidder $i$ can bid up to $C_{i}$ units of cash, but cannot bid above that at any cost. ${ }^{14}$ First, we consider a model with exogenous means of payments. Then, we make them endogenous by introducing cash constraints into the model.

\section{Initiation with Exogenous Means of Payments}

First, we solve the model with exogenous means of payments. In particular we consider three cases. In the first case, both bidders always compete in cash bids. In the second case, both bidders always compete in stock bids. Finally, in the third case, one bidder competes in cash bids and the other bidder competes in stock bids. While the means of payments are exogenous in this part of the paper,

\footnotetext{
${ }^{12}$ This result was established first by Hansen (1985). See Rhodes-Kropf and Viswanathan (2000) and DeMarzo, Kremer, and Skrzypacz (2005) for generalizations of it.

${ }^{13}$ According to the first reason, bidders use stock bids whenever it is overpriced by the market. See Myers and Majluf (1984) for the general argument and Rhodes-Kropf and Viswanathan (2004) for a specific model. According to the second reason, stock bids induce targets to make more efficient acceptance decisions. See Hansen (1987) and Fishman (1989).

${ }^{14}$ Our qualitative results hold as long as cash limits of the bidders grow at a slower rate than the target.
} 
this model will provide much of the intuition behind the model with endogenous means of payments.

\section{II.A Two Cash Bidders}

Consider the case in which both bidders make offers in cash. Suppose that a takeover contest is initiated at time $t$ and both bidders compete for the target in an English auction. A weakly dominant strategy for bidder $i$ is to bid up to $b_{i}$, where

$$
\Pi_{b}+v_{i} X_{t}-b_{i}=\Pi_{o}
$$

Intuitively, each bidder is willing to bid up to a point at which his payoff from acquiring the target $\left(\Pi_{b}+v_{i} X_{t}-b_{i}\right)$ is exactly equal to his payoff from losing the contest to the rival $\left(\Pi_{o}\right)$. Therefore, the bidder with the highest valuation acquires the target and pays $\min \left(v_{1}, v_{2}\right) X_{t}+\Delta$.

Conjecture that the bidder with valuation $v$ finds it optimal to initiate the contest at threshold $\bar{X}_{c}(v)$ provided that the other bidder has not initiated the contest yet, where $\bar{X}_{c}(v)$ is decreasing in $v$. If the bidder with valuation $v$ wins the contest for target $X_{t}$ against the bidder with valuation $w$, the change in his value relative to the stand-alone level is

$$
(v-w) X_{t}-\Delta
$$

If, on the other hand, the bidder loses, the corresponding difference is $-\Delta$. If the bidder with synergy $v$ initiates the contest at threshold $\bar{X}$, his expected payoff at the initial date is

$$
\begin{aligned}
& \left(\frac{X_{0}}{\bar{X}}\right)^{\beta} \int_{\underline{v}}^{\bar{X}_{c}^{-1}(\bar{X})}(\bar{X} \max \{v-w, 0\}-\Delta) d F(w) \\
& +\int_{\bar{X}_{c}^{-1}(\bar{X})}^{\bar{v}}\left(\frac{X_{0}}{\bar{X}_{c}(w)}\right)^{\beta}\left(\bar{X}_{c}(w) \max \{v-w, 0\}-\Delta\right) d F(w),
\end{aligned}
$$

where $\beta>1$ is the positive root of the fundamental quadratic equation $\frac{1}{2} \sigma^{2} \beta(\beta-1)+\mu \beta-r=0$. The second multiplicand in each term of (5) is the change in the value of the bidder from the auction relative to the stand-alone level, and the first multiplicand is the price of the contingent claim that pays $\$ 1$ at the time when the auction occurs. The first (second) term of (5) corresponds to the case in which the bidder with valuation $v$ (his competitor) initiates the auction. Maximizing (5) with respect 
to $\bar{X}$ and applying the equilibrium condition that the maximum is reached at $\bar{X}_{c}(v)$, we obtain

$$
\bar{X}_{c}(v)=\frac{\beta}{\beta-1} \frac{\Delta}{v-\mathbb{E}[w \mid w \leq v]} .
$$

This equation is intuitive. Because of the option to delay approaching the target, a bidder approaches the target only at a point when his expected surplus from initiating the contest exceed the costs by a high enough margin. The increase in the target's efficiency that is captured by the acquirer in expectation is $(v-\mathbb{E}[w \mid w \leq v]) X_{t}$, and the cost of approaching the target is $\Delta$. The term $\beta /(\beta-1)>$ 1 captures the degree to which the option to delay approaching the target is important.

By assumption, the bidder's surplus from winning the contest less what he pays in expectation, $v-\mathbb{E}[w \mid w \leq v]$, is increasing in $v$. Hence, $\bar{X}_{c}(v)$ is indeed decreasing in the synergy parameter $v$. This monotonicity has two implications. First, it implies that targets with higher potential synergies are acquired earlier. Second, it implies that the bidder that approaches the target is the bidder with the higher valuation. In this model, it follows that in equilibrium, the bidder that approaches the target always wins the auction. ${ }^{15}$ In a more general setting, in which bidders can update their valuations after the contest initiation (e.g., during due diligence), this result would not hold, but the bidder that initiates the contest would always win with a higher probability that his competitor, provided that the degree of initial information is the same for both bidders.

Another interesting property of (6) is that bidders with valuations $v>\underline{v}$ find it optimal to initiate the takeover contest at some finite $\bar{X}_{c}(v)$. This is because, as (4) shows, there always exists high enough $X_{t}$ such that the winning bidder receives a positive surplus for any $w<v$. As long as $v>\underline{v}$, the competitors have lower valuations than the initiating bidder with probability one which results in a positive expected surplus for high enough $X_{t}$ and, a result, in a finite initiation threshold.

The equilibrium is summarized in the following proposition:

Proposition 1. The symmetric equilibrium in the joint entry-bidding game when both bidders always make bids in cash is as follows. A bidder with the valuation parameter $v$ approaches the target at threshold $\bar{X}_{c}(v)$, given by (6), provided that no bidder has approached the target before. In the auction, bidder $i$ progressively increases his bid until it reaches $b_{i}=v_{i} X_{t}+\Delta$ or until the other bidder drops out. The bidder with the higher synergy parameter initiates the contest and acquires the target.

\footnotetext{
${ }^{15}$ This result does not hold in the general model, in which the bidders are asymmetric with respect to their means of payments or cash constraints.
} 
In the special case of the uniform distribution of $v$ over $[\underline{v}, \bar{v}], \mathbb{E}[w \mid w<v]=(\underline{v}+v) / 2$. Therefore,

$$
\bar{X}_{c}(v)=\frac{\beta}{\beta-1} \frac{2 \Delta}{v-\underline{v}} .
$$

It is easy to see that $\bar{X}_{c}(v)$ is indeed a decreasing function of $v$.

\section{II.B Two Stock Bidders}

Now, consider the case in which both bidders make offers in stock. It is instructive to expand the definition of a "button" auction to the case of stock bids. An auctioneer sets the initial fraction of the combined company to zero and gradually raises it. Each bidder confirms his participation continuously until the fraction of the combined company to be paid is too high and forces him to withdraw from the auction. As soon as only one bidder remains, he is declared the winner and pays the current fraction of the combined company. It immediately follows that a weakly dominant strategy for bidder $i$ competing for target $X_{t}$ is to bid up to $\alpha_{i}$, where

$$
\left(1-\alpha_{i}\right)\left(\Pi_{b}+v_{i} X_{t}\right)=\Pi_{o}
$$

Intuitively, as in the case of cash offers, each bidder is willing to bid up to a level at which his remaining payoff $\left(\left(1-\alpha_{i}\right)\left(\Pi_{b}+v_{i} X_{t}\right)\right)$ is exactly equal to his payoff from losing the contest to the rival $\left(\Pi_{o}\right)$. It is easy to show that the value of this offer to the target is equal to (3). Suppose that a bidder with the valuation parameter $v$ wins against the bidder with the valuation parameter $w \leq v$. Then, he pays a fraction

$$
1-\frac{\Pi_{o}}{\Pi_{b}+w X_{t}}
$$

to the target. Note that the winner's payment is a proportion of the combined entity under the new management and therefore depends on the winner's synergies, while the share he pays is determined by the synergies of his competitor. Because the value of the stock payment increases in the bidder's valuation, the value of the winner's payment in this case is higher than in the case of an all-cash contest against the same competitor. More precisely, the change in the winner's value relative to the stand-alone level is

$$
\frac{\Pi_{o}(v-w) X_{t}}{\Pi_{b}+w X_{t}}-\Delta
$$


Note that $\Pi_{o} /\left(\Pi_{b}+w X_{t}\right)<1$. It immediately follows that a bidder always obtains less surplus from competing in stock than in cash.

Conjecture that bidder with valuation $v$ finds it optimal to initiate the contest at threshold $\bar{X}_{s}(v)$ provided that the other bidder has not initiated the contest yet, where $\bar{X}_{s}(v)$ is decreasing in $v$. If the bidder with synergy $v$ initiates the contest at threshold $\bar{X}$, his expected payoff at the initial date is

$$
\begin{aligned}
& \left(\frac{X_{0}}{\bar{X}}\right)^{\beta} \int_{\underline{v}}^{\bar{X}_{s}^{-1}(\bar{X})}\left(\frac{\Pi_{o}}{\Pi_{b}+w \bar{X}} \bar{X} \max \{v-w, 0\}-\Delta\right) d F(w) \\
& +\int_{\bar{X}_{s}^{-1}(\bar{X})}^{\bar{v}}\left(\frac{X_{0}}{\bar{X}_{s}(w)}\right)^{\beta}\left(\frac{\Pi_{o}}{\Pi_{b}+w \bar{X}_{s}(w)} \bar{X}_{s}(w) \max \{v-w, 0\}-\Delta\right) d F(w),
\end{aligned}
$$

Similarly to the case of two cash bidders, the first (second) term of (11) reflects the case in which the bidder with synergy $v$ (his competitor) initiates the auction. Maximizing (11) with respect to $\bar{X}$ and applying the equilibrium condition that the maximum is reached at $\bar{X}_{s}(v)$, we obtain

$$
\mathbb{E}\left[\frac{\Pi_{o}\left(\Pi_{b}+\frac{\beta}{\beta-1} w \bar{X}_{s}(v)\right)}{\left(\Pi_{b}+w \bar{X}_{s}(v)\right)^{2}}(v-w) \mid w \leq v\right] \bar{X}_{s}(v)=\frac{\beta}{\beta-1} \Delta .
$$

As with (6), the left-hand side is a strictly increasing function of $\bar{X}$, which verifies the conjecture that the optimal approaching policy of each bidder is given by the upper trigger $\bar{X}_{s}(v)$. In particular, monotonicity implies that if the trigger exists, it is unique. However, (12) does not have a solution for some $v \in[\underline{v}, \bar{v}]$. By monotonicity, the highest value of the left-hand side of (12) is

$$
\lim _{\bar{X} \rightarrow \infty} \mathbb{E}\left[\frac{\Pi_{o}\left(\Pi_{b}+\frac{\beta}{\beta-1} w \bar{X}\right) \bar{X}}{\left(\Pi_{b}+w \bar{X}\right)^{2}}(v-w) \mid w \leq v\right]=\frac{\beta}{\beta-1} \Pi_{o} \mathbb{E}\left[\frac{v-w}{w} \mid w \leq v\right]
$$

This value decreases in $v$ and reaches zero when $v=\underline{v}^{16}$ Thus, once $v$ decreases to a sufficiently low level $v^{*}$, given by

$$
\mathbb{E}\left[\frac{v^{*}-w}{w} \mid w \leq v^{*}\right]=\frac{\Delta}{\Pi_{o}},
$$

no bidder finds it optimal to approach the target, even though it is socially optimal to do so when $X_{t}$ is high enough. The intuition can be seen from (10). As $X_{t} \rightarrow \infty$, the bidder with valuation $v$ only

\footnotetext{
${ }^{16}$ To see that the value decreases in $v$, differentiate it with respect to $v$. The derivative is

$$
-\frac{\beta}{\beta-1} \Pi_{o} \int_{\underline{v}}^{v} \frac{v-w}{w} \frac{f(w) f(v)}{F(v)^{2}} d w<0 .
$$
}


obtains a limited revenue, $\Pi_{o} \frac{v-w}{w}-\Delta$, in a contest against the bidder with valuation $w$. The reason for the limited bidder revenue in the case of stock bids is that in the model, the relative size of the bidders and the target changes in time. As $X_{t}$ increases, for the same $v$, the bidder has to give away a larger portion of the combined company to the target. As a result, the expected revenue of the bidder with valuation $v$ is also limited from above as $X_{t} \rightarrow \infty$. For sufficiently low $v$, the bidder prefers to remain standalone; the threshold $v^{*}$ is given above.

The equilibrium is summarized in the following proposition:

Proposition 2. The symmetric equilibrium in the joint entry-bidding game when both bidders always make bids in stock is as follows. If the synergy parameter of a bidder is $v>v^{*}$, where $v^{*}$ is defined by (14), then he approaches the target at threshold $\bar{X}_{s}(v)$, given by (12), provided that no bidder has approached the target before. If $v \leq v^{*}$, then a bidder never approaches the target first. In the auction, bidder $i$ progressively increases his bid until it reaches $\alpha_{i}\left(v_{i}\right)$, given by (8) or until the other bidder drops out. If $\max \left(v_{1}, v_{2}\right)>v^{*}$, the bidder with the higher synergy parameter initiates the contest and acquires the target. If $\max \left(v_{1}, v_{2}\right) \leq v^{*}$, the takeover never occurs.

While there is no analytical solution for $\bar{X}_{s}(v)$, it is easy to study its properties. In particular, it is interesting to see how (12) relates to (6). For this purpose, it is convenient to decompose (12) into two parts:

$$
\mathbb{E}\left[\frac{\Pi_{o}(v-w) \bar{X}}{\Pi_{b}+w \bar{X}} \mid w \leq v\right]+\frac{1}{\beta-1} \mathbb{E}\left[\frac{\Pi_{o}(v-w) w \bar{X}^{2}}{\left(\Pi_{b}+w \bar{X}\right)^{2}} \mid w \leq v\right]=\frac{\beta}{\beta-1} \Delta
$$

The left-hand side of (15) consists of two components. The first component is the surplus that the bidder obtains in expectation. It is always below the left-hand side of (6), because separation is costlier is stock than in cash. If this were the only term on the left-hand side of (15), then each bidder would always find it optimal to approach the target later if he bids in stock. However, (15) contains an additional positive second term. It corresponds to the effect that the delay causes the surplus of the bidder to increase at a slower pace when the bidder makes bids in stock. Alternatively, one can think of this term as a part of the delay cost on the right-hand side of (15): when $X_{t}$ is higher, further delay is less costly to the bidder as further increase in $X_{t}$ has a negative effect of a smaller magnitude on the bidder revenue. The magnitude of this effect depends on the value of delay parameter $\beta /(\beta-1)$. The following proposition shows that if $\beta /(\beta-1)$ is not too high, then this additional effect is dominated 
by the first effect, so the bidder always approaches the target earlier if he bids in cash:

Proposition 3. Suppose that the measure of the option value of delay, $\beta /(\beta-1)$, is not too high:

$$
\frac{\beta}{\beta-1}<2 \frac{\Pi_{b}}{\Pi_{o}}
$$

Then, $\bar{X}_{s}(v)>\bar{X}_{c}(v)$ for any $v$.

For standard parameters, the multiplier of the delay option, $\beta /(\beta-1)$, does not exceed 2. As a consequence, condition (16) holds, so other things equal the bidder approaches the target later if he bids in stock. However, if the multiplier of the delay option is very high, then the stock bidder can approach the target earlier than the cash bidder, despite obtaining a lower fraction of the total surplus in expectation. As an example, consider an extreme case in which the multiplier of the delay option is infinite, $\beta /(\beta-1) \rightarrow \infty$ (or equivalently, $\beta \rightarrow 1$ ). Then, the optimal threshold of the cash bidder is $\bar{X}_{c}(v) \rightarrow \infty$ for all $v$. By contrast, (15) implies that the optimal threshold of the stock bidder $\bar{X}_{s}(v)$ solves

$$
\mathbb{E}\left[\Pi_{o} \frac{(v-w) w \bar{X}_{s}(v)^{2}}{\left(\Pi_{b}+w \bar{X}_{s}(v)\right)^{2}} \mid w \leq v\right]=\Delta .
$$

In particular, it is finite for all $v>v^{*}$. Thus, if $\beta /(\beta-1)$ is very high, then stock bidders with high enough $v$ approach the target earlier than cash bidders. However, it is never the case that stock bidders approach the target earlier than cash bidders uniformly for all $v$ : if $v$ is low enough, $\bar{X}_{c}(v)$ is always below $\bar{X}_{s}(v)$ even if condition (16) does not hold.

In the rest of the paper we assume that realistic condition (16) holds. We refer to this case as the "normal" case.

\section{II.C Cash vs. Stock Bidder}

Finally, consider the case in which one bidder makes bids in cash and the other bidder makes bids in stock. In this case, as well as in the model with endogenous means of payment of Section III, bidders make bids in different securities. Before proceeding with the analysis, we extend the formalization of the English auction for bids from different security sets. The following definition puts a formal structure on the English auction: 
Definition (English auction for bids in combinations of stock and cash). The auctioneer sets the starting price to zero and gradually rises it. A price $p$ corresponds to either a payment of $p$ dollars in cash or a payment of any $b \in[0, p]$ dollars in cash and a fraction $\alpha(b, p)$ in the stock of the combined company defined below. As $p$ gradually rises, a bidder confirms his participation until he decides to withdraw from the auction. As soon as only one bidder remains, he is declared the winner and pays any element of his choice from set $\{(b, \alpha(b, p), b \in[0, p])\}$, corresponding to price $p$ at which his competitor dropped. $\alpha(b, p)$ is such that a bidder who withdraws at price $p$ is indifferent between all elements of set $\{(b, \alpha(b, p), b \in[0, p])\}$ :

$$
\alpha(b, p)=\frac{p-b}{\Pi_{o}+p}
$$

This formalization extends the standard "button" model of an English auction for all-cash bids (Milgrom and Weber, 1982), as well as the analogous model for all-stock bids (Hansen, 1985). If bidders always bid in cash, the definition is equivalent to an auction in which the seller gradually rises the cash price, which the winner pays once his rival withdraws. Similarly, if bidders always bid in stock, the definition is equivalent to an auction in which the seller gradually rises the proportion of the combined company, which the winner pays once his rival withdraws. The indifference condition for $\alpha(b, p)$ means that the decision of a bidder to drop from the auction is only driven by his valuation and not the security he is bidding with. To obtain (18), note that the bidder with valuation $v$ withdraws at price $p$ if and only if

$$
(1-\alpha)\left(\Pi_{b}+v X_{t}\right)=b+\Pi_{o} \Rightarrow v X_{t}+\Pi_{b}=\frac{b+\Pi_{o}}{1-\alpha}
$$

The indifference condition requires $\left(b+\Pi_{o}\right) /(1-\alpha)$ to be the same for all $b \in[0, p]$ and yields (18). In the case considered here, the stock bidder does not have cash, so for him, $b=0, \alpha(b, p)=\frac{p}{\Pi_{o}+p}$.

Without loss of generality, we call the cash bidder "bidder 1" and the stock bidder "bidder 2." Suppose that an auction takes place at time $t$. If the synergy parameter of bidder 1 is equal to $v_{1}$, bidder 1 is willing to offer up to $b\left(v_{1}\right)=p\left(v_{1}\right)=v_{1} X_{t}+\Delta$. If the synergy parameter of bidder 2 is equal to $v_{2}$, bidder 2 is willing to offer up to $\alpha\left(v_{2}\right)$, given by (8). The cash value of this bid is equal to $p\left(v_{2}\right)=v_{2} X_{t}+\Delta$. If $v_{1}>v_{2}$, then bidder 1 is the winning bidder, and he pays according to the maximum value that bidder 2 is willing to offer, $v_{2} X_{t}+\Delta$. If $v_{2}>v_{1}$, then bidder 2 is the winning bidder, and he has to pay a fraction of the combined company corresponding to the maximum cash bid that bidder 1 is willing to offer, $\alpha\left(v_{1}\right) \equiv \alpha\left(b\left(v_{1}\right), p\left(v_{1}\right)\right)$. In other words, the winning bidder of 
each type (cash or stock) makes a payment that only depends on his but not his competitor's type.

We assume that the equilibrium in strictly decreasing initiation strategies of both bidders, $\bar{X}_{1}(v)$ and $\bar{X}_{2}(v)$, exists. This is the case in all of our numerical examples. We do not make any assumptions about ordering of the two strategies but later provide conditions under which such ordering can be established. First, if bidder 1 with valuation $v$ approaches the target at threshold $\bar{X}$, his expected payoff at the initial date equals ${ }^{17}$

$$
\begin{aligned}
& \left(\frac{X_{0}}{\bar{X}}\right)^{\beta} \int_{\underline{v}}^{\bar{X}_{2}^{-1}(\bar{X})}(\bar{X} \max \{v-w, 0\}-\Delta) d F(w) \\
& +\int_{\bar{X}_{2}^{-1}(\bar{X})}^{\bar{v}}\left(\frac{X_{0}}{\bar{X}_{2}(w)}\right)^{\beta}\left(\bar{X}_{2}(w) \max \{v-w, 0\}-\Delta\right) d F(w) .
\end{aligned}
$$

Intuitively, if valuation of bidder 2 is below $\bar{X}_{2}^{-1}(\bar{X})$, bidder 1 initiates the contest at threshold $\bar{X}$. Otherwise, the contest is initiated by bidder 2. If the contest is initiated at some $X_{t}$ and valuation of bidder $1, v$, is above valuation of bidder $2, w$, then bidder 1 wins the auction, makes a payment in cash and is left with the revenue equal to $X_{t}(v-w)-\Delta$. If $v<w$, he loses the auction and suffers the loss of $\Delta$. Maximizing (20) with respect to $\bar{X}$ and applying the equilibrium condition that the maximum is reached at $\bar{X}_{1}(v)$, we obtain

$$
\bar{X}_{1}(v)=\frac{\beta}{\beta-1} \frac{\Delta}{v-\mathbb{E}[w \mid w \leq \Omega(v)]} \Psi(v)
$$

where for bidder $i$ and his competitor $-i, \Omega(v)=\min \left\{v, \bar{X}_{-i}^{-1}\left(\bar{X}_{i}(v)\right)\right\}$ and $\Psi(v) \equiv \max \left\{1, \frac{F\left(\bar{X}_{-i}^{-1}\left(\bar{X}_{i}(v)\right)\right)}{F(v)}\right\}$. Note that (21) is very similar to (6). To see the intuition for the difference, consider, without loss of generality, $\bar{X}_{1}(v)<\bar{X}_{2}(v)$. Then for bidder $1, \Omega(v)=v, \Phi(v) \geq 1$. Consequently, bidder 1 delays his decision to approach the target compared to the case in which he faces another cash bidder: $\bar{X}_{1}(v) \leq \bar{X}_{c}(v)$. Intuitively, because other things equal bidder 2 with the same valuation approaches the target later than bidder 1, upon approaching bidder 1 faces a stronger competitor than if he faced a cash bidder. Because of this, bidder 1 faces a lower probability of winning the auction, which decreases his expected surplus. Consequently, he further delays his decision to approach the target.

Second, if bidder 2 with valuation $v$ approaches the target at threshold $\bar{X}$, his expected payoff at

\footnotetext{
${ }^{17}$ Here and hereafter, we use $\bar{X}_{i}^{-1}(\bar{X}), i=\{1,2\}$ instead of the more precise $\min \left\{\bar{X}_{i}^{-1}(\bar{X}), \bar{v}\right\}$ to save on notation.
} 
time 0 is equal to

$$
\begin{aligned}
& \left(\frac{X_{0}}{\bar{X}}\right)^{\beta} \int_{\underline{v}}^{\bar{X}_{1}^{-1}(\bar{X})}\left(\frac{\Pi_{0}}{\Pi_{b}+w \bar{X}} \bar{X} \max \{v-w, 0\}-\Delta\right) d F(w) \\
& +\int_{\bar{X}_{1}^{-1}(\bar{X})}^{\bar{v}}\left(\frac{X_{0}}{\bar{X}_{1}(w)}\right)^{\beta}\left(\frac{\Pi_{0}}{\Pi_{b}+w \bar{X}_{1}(w)} \bar{X}_{1}(w) \max \{v-w, 0\}-\Delta\right) d F(w) .
\end{aligned}
$$

This expression is similar to (20), with the only difference that bidder 2 pays stock if he wins the contest and is left with the revenue equal to $\left(\frac{\Pi_{0}}{\Pi_{b}+w X_{t}} X_{t} \max \{v-w, 0\}-\Delta\right)$. Maximizing (22) with respect to $\bar{X}$ and applying the equilibrium condition that the maximum is reached at $\bar{X}_{2}(v)$, we obtain

$$
\mathbb{E}\left[\frac{\Pi_{o}\left(\Pi_{b}+\frac{\beta}{\beta-1} w \bar{X}_{2}(v)\right)}{\left(\Pi_{b}+w \bar{X}_{2}(v)\right)^{2}}(v-w) \mid w \leq \Omega(v)\right] \bar{X}_{2}(v)=\frac{\beta}{\beta-1} \Delta \Psi(v) .
$$

Note that (23) is very similar to (12). To see the intuition for the difference, again, consider $\bar{X}_{1}(v)<$ $\bar{X}_{2}(v)$, so that for bidder $2, \Omega(v)<v$ and $\Psi(v)=1$. Because $w$ takes lower values compared to the case in which bidder 2 faces another stock bidder, bidder 2 accelerates his decision to approach the target: $\bar{X}_{2}(v) \geq \bar{X}_{s}(v)$. Intuitively, because other things equal bidder 1 with the same valuation approaches the target earlier than bidder 2, upon approaching bidder 2 faces a weaker competitor than if he faced another stock bidder. Because of this, bidder 2 obtains a higher expected surplus from the auction, which accelerates his decision to approach the target.

The equilibrium is summarized in the following proposition:

Proposition 4. The separating equilibrium in the joint entry-bidding game between the stock and the cash bidder takes the following form. The initiation strategy of bidder 1 (the cash bidder) with the synergy parameter $v_{1}$ is to approach the target at threshold $\bar{X}_{1}\left(v_{1}\right)$, given by (21), provided that no bidder has approached the target before. The initiation strategy of bidder 2 (the stock bidder) with the synergy parameter $v_{2}>v_{2}^{*}$ is to approach the target at threshold $\bar{X}_{2}\left(v_{2}\right)$, given by (23), provided that no bidder has approached the target before. If $v_{2} \leq v_{2}^{*}$, then bidder 2 never approaches the target first. The boundary type $v^{*}$ is given by

$$
v_{2}^{*}=\frac{\Pi_{b}}{\Pi_{o}} \underline{v}>\underline{v}
$$

In the auction, bidder 1 progressively increases his cash bid until it reaches $b\left(v_{1}\right)=v_{1} X_{t}+\Delta$ or until bidder 2 drops out; bidder 2 progressively increases his stock bid until it reaches fraction $\alpha\left(v_{2}\right)$, given 
by (8) or until the other bidder drops out.

As in the case of two stock bidders, expecting low revenue from acquiring the target in stock, the stock bidder does not initiate the takeover contest for valuations equal to or below $v_{2}^{*}$. There is no analytical solution for the jointly determined $\bar{X}_{1}(v)$ and $\bar{X}_{2}(v)$ but two closed form equations can be obtained for $\bar{X}_{1}^{-1}(X)$ and $\bar{X}_{2}^{-1}(X)$ which make the numerical analysis of the strategies easy. Appendix B provides more detail.

Proposition 5 establishes ordering of strategies in the three cases of exogenous means of payment for standard parameters, such that $\beta /(\beta-1)$ does not exceed 2 :

Proposition 5. If equilibria in strictly decreasing initiation strategies $\bar{X}_{c}(v) ; \bar{X}_{s}(v)$; and $\bar{X}_{1}(v)$, $\bar{X}_{2}(v)$ exist and $\frac{\beta}{\beta-1}<2 \frac{\Pi_{b}}{\Pi_{o}}$ then the strategies are ordered: $\bar{X}_{s}(v)>\bar{X}_{2}(v)>\bar{X}_{1}(v)>\bar{X}_{c}(v)$ for any $v$.

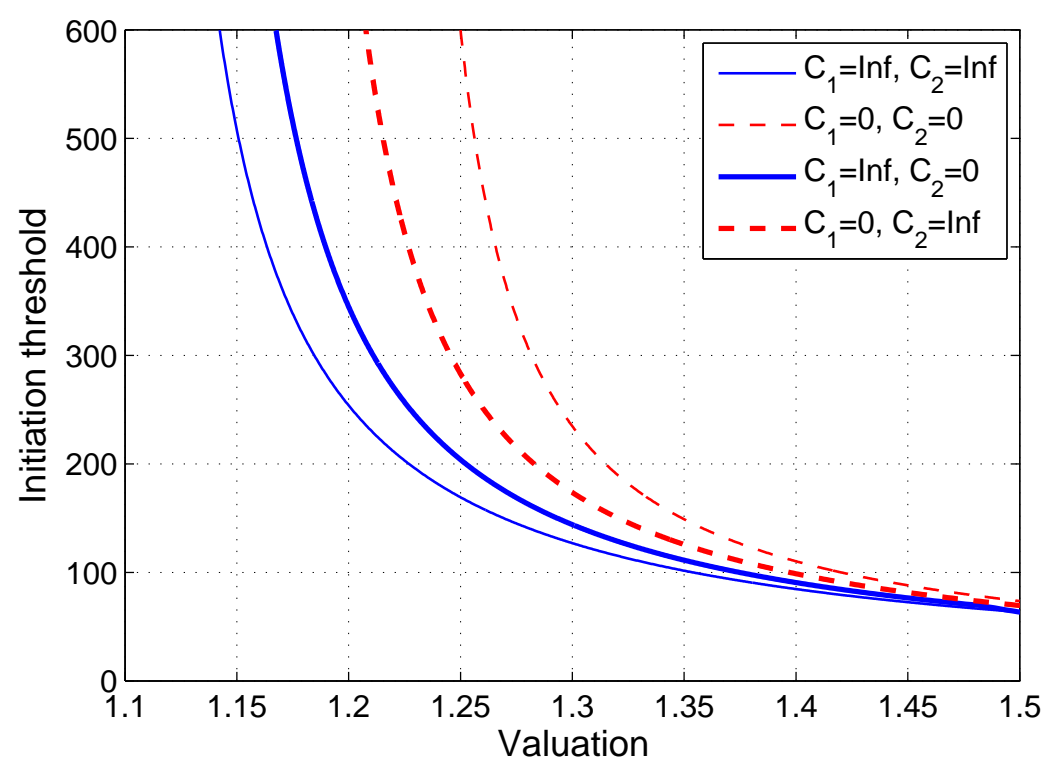

Figure 1: Initiation strategies of cash and stock bidders facing different types of competitors. The figure shows the optimal initiation strategies of bidders as a function of their valuations, $v$. The thin solid (thin dashed) line is the strategy of a cash (stock) bidder facing another cash (stock) bidder; the thick solid (thick dashed) line is the strategy of a cash (stock) bidder facing a stock (cash) bidder.

For the numerical example, we choose the benchmark model parametrization: $r=0.05, \mu=0.01$, $\sigma=0.25, \underline{v}=1.1, \bar{v}=1.5, v \sim \operatorname{Uniform}[\underline{v}, \bar{v}], \Pi_{b}=100, \Pi_{o}=95$. These values are also reported in Table I. Specifically, the benchmark case considers acquisition of a target whose assets grow at rate $\mu$ typically used in dynamic models of the firm, and who has the average COMPUSTAT asset 
volatility $\sigma$. The losing bidder's profits are $5 \%$ below the pre-acquisition levels. The average synergies are equal to $30 \%$ of the target's core business. The interest rate is set at constant $5 \%$. The benchmark parametrization satisfies $\beta /(\beta-1)<2$.

Figure 1 shows the four thresholds for our benchmark parametrization as a function of bidders' valuations, $v$. A higher probability of losing the takeover contest makes a cash bidder that competes against a stock bidder more cautious compared to the case when he competes against another cash bidder. As a result, his initiation threshold increases. The opposite is also true: a lower probability of losing the takeover contest makes a stock bidder more aggressive when he competes against a cash bidder. As a result, his initiation threshold decreases. Another interesting result is that competing against a cash bidder not only directly accelerates the initiation by a stock bidder but also makes stock bidders with lower valuations willing to initiate in the first place: $v_{2}^{*}<v^{*}$. As a result, both effects combine so that initiation of takeover contests is sped up and happens more frequently when at least one of the bidders is able to bid cash.

\section{Initiation with Endogenous Means of Payments}

In the previous section we solved for the optimal initiation thresholds assuming that means of payments of each bidder is exogenous. In this section, we make them endogenous by introducing cash constraints of bidders to the economy: specifically, bidder $i$ can only bid up to $C_{i} \geq 0$ in cash. Throughout the section, we assume that the equilibrium with strictly decreasing initiation strategies of both bidders, $X_{1}(v)$ and $X_{2}(v)$, exists. This is the case in all of our numerical examples.

Consider the auction that occurs at time $t$. Suppose that valuations of bidder $i$ and $j$ are $v$ and $w<v$, respectively. At any price $p$ during the course of the auction at which bidder $j$ has not withdrawn yet, bidder $i$ prefers not to withdraw. Therefore, bidder $j$ withdraws first. Because at the withdrawal point, bidder $j$ is indifferent between all elements of the set $(b, \alpha)$, his withdrawal price point $p$ is such that he is indifferent between acquiring the target for $p$ in cash and taking the outside option: $p=w X_{t}+\Delta$. Once bidder $j$ withdraws, bidder $i$ selects the element of the set $(b, \alpha)$ yielding the lowest expected payment. Because bidder $j$ is indifferent between all elements of the set and the valuation of bidder $i$ is higher, the payment of bidder $i$ is minimized if the cash amount in the payment is maximized. If $C_{i} \geq w X_{t}+\Delta$, bidder $i$ acquires the target by paying $w X_{t}+\Delta$ in cash. Otherwise, 
bidder $i$ acquires the target by paying $C_{i}$ in cash and fraction

$$
\alpha\left(C_{i}, w X_{t}+\Delta\right)=1-\frac{\Pi_{o}+C_{i}}{\Pi_{b}+w X_{t}}
$$

of the combined company. In the former case, the change in the value of bidder $i$ relative to the stand-alone value is

$$
(v-w) X_{t}-\Delta
$$

In the latter case, it is

$$
\begin{aligned}
& \frac{\Pi_{o}+C_{i}}{\Pi_{b}+w X_{t}}(v-w) X_{t}-C_{i}-\Pi_{b} \\
= & \left(\Pi_{o}+C_{i}\right) \frac{(v-w) X_{t}}{\Pi_{b}+w X_{t}}-\Delta .
\end{aligned}
$$

Consider the decision of bidder $i$ with valuation $v$ to initiate the contest. If bidder $i$ approaches the target at threshold $\bar{X}$, his expected payoff at the initial date equals

$$
\begin{aligned}
& \left(\frac{X_{0}}{\bar{X}}\right)^{\beta} \int_{\underline{v}}^{\bar{X}_{-i}^{-1}(\bar{X})}\left(\min \left\{\frac{\Pi_{o}+C_{i}}{\Pi_{b}+w \bar{X}}, 1\right\} \bar{X} \max \{v-w, 0\}-\Delta\right) d F(w) \\
& +\int_{\bar{X}_{-i}^{-1}(\bar{x})}^{\bar{v}}\left(\frac{X_{0}}{\bar{X}_{-i}(w)}\right)^{\beta}\left(\min \left\{\frac{\Pi_{o}+C_{i}}{\Pi_{b}+w \bar{X}_{-i}(w)}, 1\right\} \bar{X}_{-i}(w) \max \{v-w, 0\}-\Delta\right) d F(w) .
\end{aligned}
$$

Intuitively, if valuation of the competitor is below $\bar{X}_{-i}^{-1}(\bar{X})$, bidder $i$ initiates the contest at threshold $\bar{X}$. Otherwise, the competitor initiates the contest at threshold $\bar{X}_{-i}(w)$. In both cases, if $v>w$, bidder $i$ wins the auction and makes a payment either in cash or in a combination of cash and stock. If $v<w$, he loses the auction and suffers the loss of $\Delta$. Maximizing (28) with respect to $\bar{X}$ and using the equilibrium condition that the maximum is reached at $\bar{X}_{i}(v)$, we obtain

$$
\begin{aligned}
& \mathbb{E}\left[\min \left\{\frac{\Pi_{o}+C_{i}}{\Pi_{b}+w \bar{X}_{i}(v)}, 1\right\}(v-w) \mid w \leq \Omega(v)\right] \bar{X}_{i}(v) \\
& +\frac{1}{\beta-1} \int_{\min \left(\frac{C_{i}-\Delta}{X_{i}(v)}, \Omega(v)\right)}^{\Omega(v)}\left(\Pi_{o}+C_{i}\right) \frac{(v-w) w \bar{X}_{i}(v)^{2}}{\left(\Pi_{b}+w \bar{X}_{i}(v)\right)^{2}} \frac{f(w)}{F(\Omega(v))} d v \\
= & \frac{\beta}{\beta-1} \Delta \Psi(v),
\end{aligned}
$$

where $\Omega(v) \equiv \min \left\{v, \bar{X}_{-i}^{-1}\left(\bar{X}_{i}(v)\right)\right\}$ and $\Psi(v) \equiv \max \left\{1, \frac{F\left(\bar{X}_{-i}^{-1}\left(\bar{X}_{i}(v)\right)\right)}{F(v)}\right\}$. The system of equations (29) for bidders 1 and 2 jointly determines equilibrium thresholds $\bar{X}_{1}(v)$ and $\bar{X}_{2}(v)$. Note that this 
solution embeds solutions for three special cases, studied in Section II. The following proposition summarizes the equilibrium:

Proposition 6. The equilibrium in the general model takes the following form. Bidder $i$ with valuation $v_{i}>v_{i}^{*}$ approaches the target at threshold $\bar{X}_{i}\left(v_{i}\right)$, provided that it has not been approached before, where $\bar{X}_{i}(v)$ satisfies (29) and $v_{i}^{*}$ is defined in Appendix A. If $v_{i} \leq v_{i}^{*}$, bidder $i$ never approaches the target first. Once the auction is initiated at time $t$, bidder $i$ progressively increases his bid until the price reaches $v X_{t}+\Delta$ or the other bidder drops out. If the other bidder drops out, bidder $i$ acquires the target for cash, if his cash balance exceeds the price at which the other bidder drops out, and for cash and stock paying $C_{i}$ in cash, otherwise.

As long as $C_{1}<\infty$ and $C_{2}<\infty$, both bidders do not initiate the takeover contest for valuations equal to or below, correspondingly, $v_{1}^{*}$ and $v_{2}^{*}$. Appendix B provides more detail on the numerical solution for $\bar{X}_{1}(v)$ and $\bar{X}_{2}(v)$.

Figure 2, Panel A shows the four thresholds (cash vs. cash bidders, stock vs. stock bidders, and bidders with internal cash $C_{1}=125$ and $C_{2}=0$ competing against each other) for our benchmark parametrization as a function of bidders' valuations, $v$. An interesting new effect compared to the case of exogenous means of payment is that for intermediate valuations, constrained bidders can choose to accelerate initiation even relative to the case of two cash bidders. This happens because they attempt to "fit into" their cash constraints. Consider Figure 2, Panels B and C that show expected bidder revenue from non-cash and cash-only deals. As the valuation of bidder 1 decreases, he initiates contests for a larger target and eventually finds himself unable to complete all deals in cash (the dashed vertical line on the right-hand side of all panels). At this stage, bidder 1 trades off costs of inefficiently early initiation against its benefits (a smaller probability that the deal is non-cash, resulting in a higher expected revenue from the auction). If the latter dominates, bidder 1 can approach a smaller target compared to the case when he is unconstrained $\left(C_{1}=0\right)$ or even to the case when both bidders are unconstrained. As the valuation of bidder 1 decreases even further (beyond the dashed vertical line on the left-hand side of all panels), any successful contest requires the payment of at least $C_{1}$ that makes fitting into cash not possible. Then, bidder 1's initiation threshold increases faster, similarly to an all-stock bidder.

Consider bidder 2 who competes against bidder 1 with $C_{1}<\infty$ instead of $C_{1} \rightarrow \infty$. Bidder 1 attempts to fit into cash and, for intermediate valuations, accelerates his initiation compared to 
$C_{1} \rightarrow \infty$, so bidder 2 becomes a stronger bidder with higher expected revenues. As a result, it is optimal for bidder 2 to also accelerate initiation for intermediate valuations.
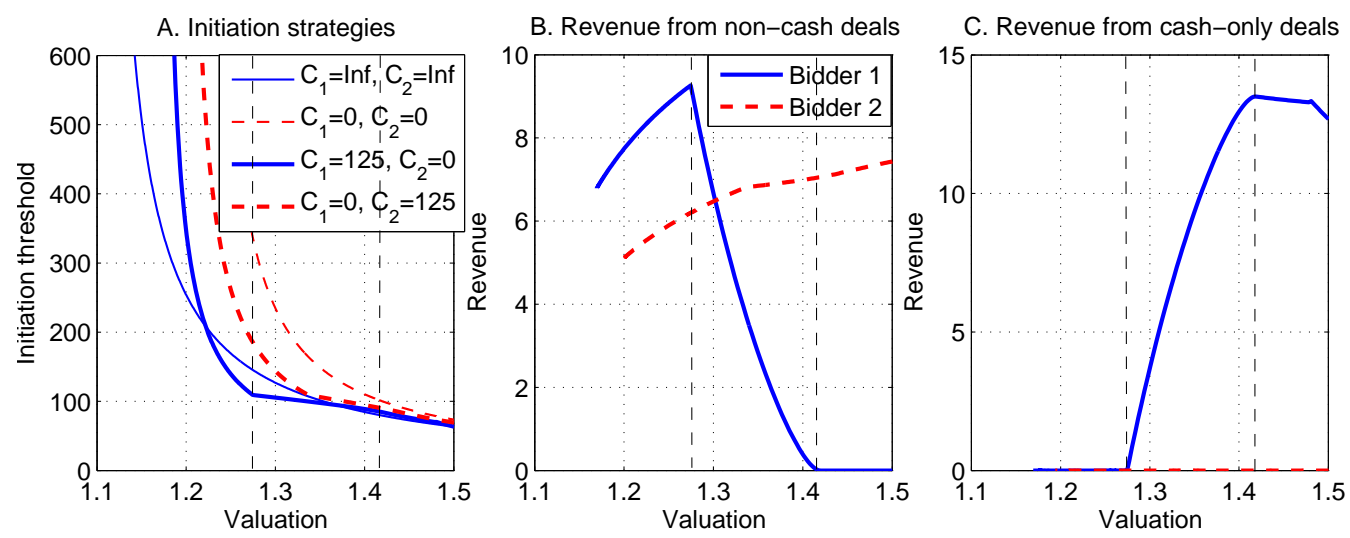

Figure 2: Initiation strategies of cash and stock bidders facing different types of competitors. Panel A shows the optimal initiation strategies of bidders as a function of their valuations, $v$. The thin solid (thin dashed) line is the strategy of a cash (stock) bidder facing another cash (stock) bidder; the thick solid (thick dashed) line is the strategy of a bidder with internal cash $C_{1}=125\left(C_{1}=0\right)$ facing a bidder with internal cash $C_{2}=0\left(C_{2}=125\right)$. Panels $\mathrm{B}$ and $\mathrm{C}$ show the part of expected bidder revenue from non-cash and cash-only deals (first line of (29)) for bidders with internal cash $C_{1}=125$ and $C_{2}=0$.

\section{Comparative Statics}

In this section, we investigate the effects of target and bidder characteristics on initiation strategies. Proposition 7 establishes comparative statics results for the general model of Section III:

Proposition 7. Assume that each bidder is, in any combination, either severely constrained $\left(C_{i}<\Delta\right)$ or unconstrained $\left(C_{i} \rightarrow \infty\right)$, and that (16) holds. Consider an equilibrium in decreasing initiation strategies $\bar{X}_{i}(v)$. For any $v, \bar{X}_{i}(v), i \in\{1,2\}$ :

1. increase in $\mu$;

2. increase in $\sigma$;

3. decrease in $r$;

4. increase in $\Delta$ (keeping $\Pi_{b}$ fixed);

5. weakly decrease in $\Pi_{b}$ (keeping $\Delta$ fixed). 
Proposition 7 provides sufficient conditions for monotone comparative statics; in addition, the numerical analysis shows that the same results hold for a wide range of cash constraints of both bidders. These results are intuitive. (1) When $\mu$ is higher, bidders wait longer before initiating the contest: the present value of costs associated with losing the deal increases due to $X_{t}$ reaching the initiation threshold of a competitor faster, and this increase dominates an increase in the present value of synergies in case of success. (2) For the same reason, when the discount rate $r$ is lower, the costs of losing the deal loom larger, so the takeover contest is initiated later. (3) Similarly, higher $\sigma$ implies a higher likelihood of the competitor reaching the initiation threshold fast, which in turn increases costs of losing the deal and leads to delay in initiation. (4) When costs of losing the contest, $\Delta$, are high, the winning bidder has to pay more to separate himself from the losing bidder: the value of the winning bidder's outside option (losing) is a negative function of $\Delta$. As a result, the bidders' expected payoffs from the contest decrease, so they initiate later. (5) The additional restrictions here make the motive to fit into cash weak, resulting in monotone comparative statics. The initiation strategies of two unconstrained bidders competing with each other are constant in $\Pi_{b}$ keeping $\Delta$ fixed. For a severely constrained bidder, however, a larger $\Pi_{b}$ results in his bidding a smaller portion of the combined company, which leads to earlier initiation, no matter the constraints of the competitor.

In case (5), it is easy to notice that when an unconstrained bidder competes against a severely constrained bidder, his initiation threshold also decreases in $\Pi_{b}$. The reason is that a higher $\Pi_{b}$ speeds up initiation by the constrained bidder. Thus, conditional on the constrained bidder not initiating yet, the unconstrained bidder faces, on average, a weaker competitor. As a result, at any hypothetical initiation threshold, the expected payoff of the unconstrained bidder from initiating the contest is higher, leading to a lower initiation threshold.

Figure 3 shows the comparative statics of the four equilibrium initiation strategies corresponding to the model in Sections II.A-II.C. The strategies are built for the benchmark model parametrization, for a bidder with the average valuation, $v=1.3$. The comparative statics are with respect to the five model parameters highlighted in Proposition 7 as well as the dispersion of the bidders' synergies. As the dispersion of the synergies increases, a bidder with synergy $v$ becomes better separated from bidders with lower synergies, and therefore on average pays less in a successful contest. As a result, the bidder initiates the contest earlier. The initiation strategies seem to be particularly sensitive to the costs of losing the deal and the dispersion of the bidders' synergies. In fact, when costs of losing the deal (the dispersion of synergies) are sufficiently high (low), the stock bidder with the average valuation never initiates the contest: his valuation is below the threshold $v^{*}\left(v_{2}^{*}\right)$ obtained in Proposition $2(3)$. 
Figure 4 depicts the comparative statics of the four equilibrium initiation strategies (two unconstrained bidders, two extremely constrained bidders $\left(C_{1}=C_{2}=0\right)$, and bidders with internal cash $C_{1}=125$ and $C_{2}=0$ competing against each other) for the benchmark model parametrization as a function of the same six model parameters. The strategies are plotted for the bidder with the average valuation, $v=1.3$. Incentives to fit into cash constraints are strong when $\mu, \sigma$ or $P_{b}$ are higher, and when $r$ is smaller. In all these cases, the combined company has a higher expected value. When means of payment are endogenous, the bidders are unwilling to share this highly-valued company with the target and choose to predominantly pay cash at the cost of earlier initialization.
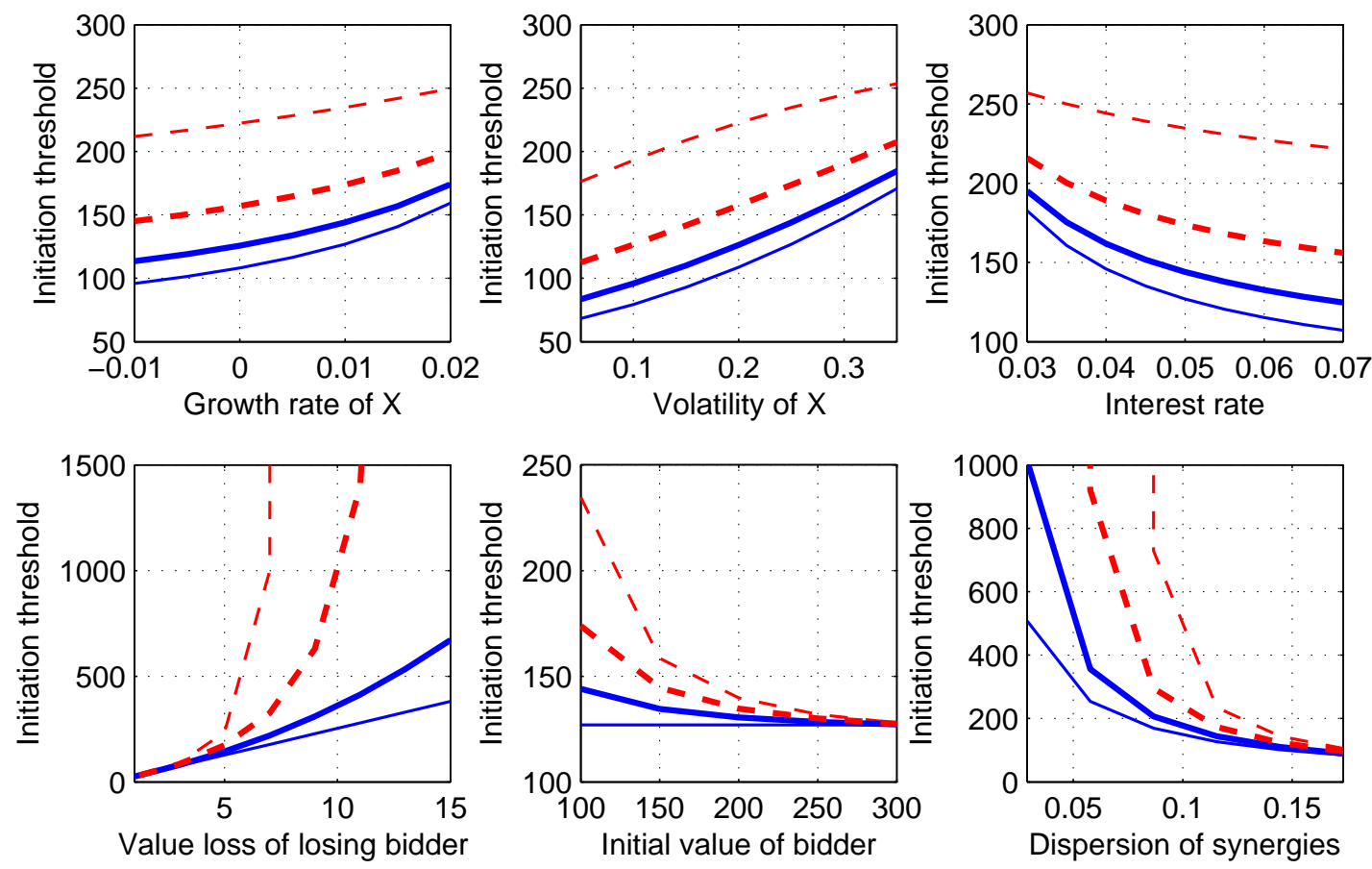

Figure 3: Initiation strategies of cash and stock bidders as a function of model parameters. The figure shows the comparative statics of the four initiation strategies for the benchmark model parametrization (Table I) and a bidder with the average valuation, $v=1.3$. The thin solid (thin dashed) line is the strategy of a cash (stock) bidder facing another cash (stock) bidder; the thick solid (thick dashed) line is the strategy of a cash (stock) bidder facing a stock (cash) bidder. The comparative statics are with respect to (i) the growth rate of a target's assets, $\mu$, (ii) the volatility of a target's assets, $\sigma$, (iii) the interest rate, $r$, (iv) costs of losing the contest, $\Delta$, (v) the initial value of bidders, $P_{b}$ (keeping $\Delta$ fixed), and (vi) the dispersion of the bidders' synergies, $D(v)$ (keeping the average valuation fixed).

Figure 5 shows the comparative statics of the optimal initiation strategies for the benchmark model parametrization and bidders with cash constraints $C_{1}$ and $C_{2}=0$, with respect to $C_{1}$. The strategies are calculated for the bidder with the average valuation, $v=1.3$. For intermediate ranges of $C_{1}$, bidder 1 has incentives to fit into cash and bidder 2, recognizing that now it faces a weaker competitor, follows by decreasing his own initiation threshold. For low and high values of $C_{1}$, all deals either require all 
available cash to be done or are always done in cash only, weakening the motives to fit into cash. As a result, strategies of both cash-constrained bidders lie between the strategies of two unconstrained and two extremely constrained bidders competing against each other.
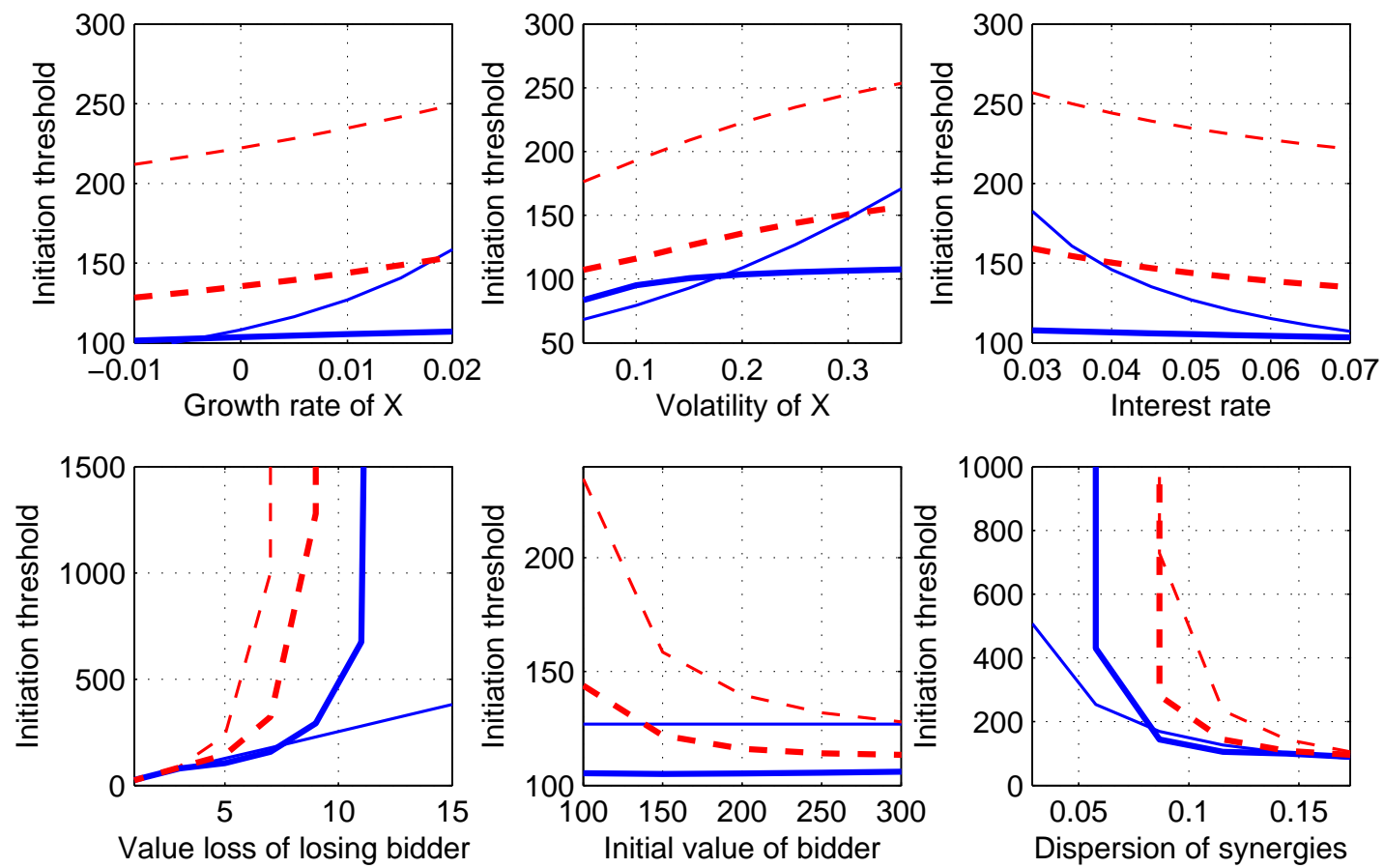

Figure 4: Initiation strategies of cash-constrained bidders as a function of model parameters. The figure shows the comparative statics of the four initiation strategies for the benchmark model parametrization (Table I) and a bidder with the average valuation, $v=1.3$. The thin solid (thin dashed) line is the strategy of an unconstrained (extremely constrained) bidder facing another unconstrained (extremely constrained) bidder; the thick solid (thick dashed) line is the strategy of a bidder with cash $C_{1}=125\left(C_{1}=0\right)$ facing a bidder with cash $C_{2}=0\left(C_{2}=125\right)$. The comparative statics are with respect to $(i)$ the growth rate of a target's assets, $\mu$, (ii) the volatility of a target's assets, $\sigma$, (iii) the interest rate, $r$, (iv) costs of losing the contest, $\Delta$, (v) the initial value of bidders, $\Pi_{b}$ (keeping $\Delta$ fixed), and (vi) the dispersion of the bidders' synergies, $D(v)$ (keeping the average valuation fixed).

In unreported results, we extend the model to the case of more than two bidders under the assumption that all bidders are either unconstrained or extremely constrained. If a bidder faces more potential competitors, his expected payoff from initiation decreases, which results in later initiation.

\section{Analysis}

The results obtained in previous sections yield a rich set of predictions. Below, we list and discuss each of them. 


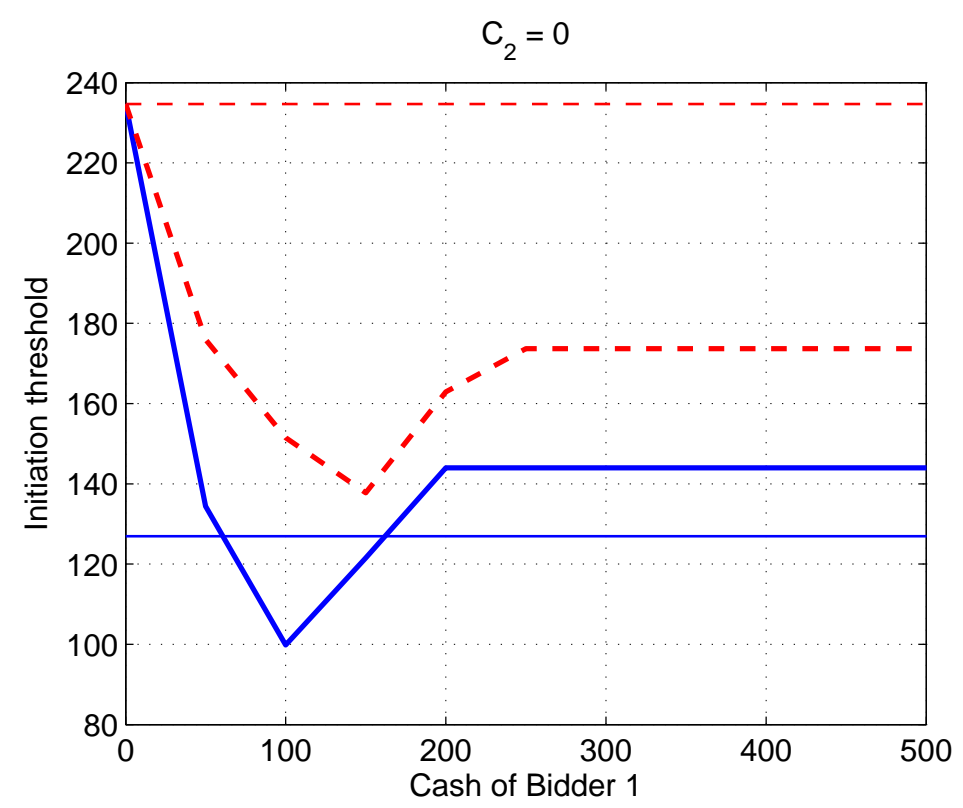

Figure 5: Initiation strategies of cash-constrained bidders as a function of asymmetries in cash constraints. The figure shows the comparative statics of the four initiation strategies for the benchmark model parametrization (Table I) as a function of cash constraints of bidder $1, C_{1}$. The comparative statics are calculated for the bidder with the average valuation, $v=1.3$. The thick solid (thick dashed) line is the strategy of a bidder with cash $C_{1}\left(C_{2}=0\right)$ facing a bidder with cash $C_{2}=0\left(C_{1}\right)$. The thin solid (thin dashed) line is the strategy of an unconstrained (extremely constrained) bidder facing another unconstrained (extremely constrained) bidder.

\section{V.A Initiation of Takeover Contests, Means of Payment, and Premiums}

A1. Companies acquired in stock are larger and older than companies acquired in cash.

Bidders with low synergies have higher benefits to wait and end up paying in stock, as compared to bidders with intermediate to high synergies who wait less, possibly trying to "fit into" their cash constraints, and pay in cash. This result can be important for empirical research as it establishes a reverse link between means of payment in takeover contests and size/age of targets. Not only are large companies acquired in non-cash deals because the bidders do not have sufficient cash; such companies were allowed to grow large because potential synergies were not high enough for bidders to acquire them small.

Figure 6 shows, for the benchmark parametrization and $C_{1}=125, C_{2}=0$, probabilities that cash and non-cash deals are completed in years 1, 2-5, 6-10, 11-25, and 26-100 ${ }^{18}$ as well as average acquisition size in deals completed by the end of year $1,5,10,25$, and 100 . The starting value of the target is such that she is on the verge of being acquired by the highest bidder with the lowest cash constraints: $X_{0}=\bar{X}_{1}(\bar{v})$. Cash deals mostly happen within the first five years of

\footnotetext{
${ }^{18}$ Formally, for each given realization of the two bidders' valuations, $v_{1}$ and $v_{2}$, the conditional probability that a
} 
the target's life while non-cash deals reach their peak in years $2-5$ and continue to be dominant types of acquisition in years 6-10. Cash deals are on average smaller and the gap in average size of cash and non-cash deals increases with the sample horizon as more and more non-cash deals are made for large targets by bidders with the lowest synergies.

While we do not directly model shocks to cash constraints, the above results make it evident that takeover activity can be spurred by two types of shocks: technology shocks that affect the potential synergies from a takeover and shocks to bidders' cash constraints. The effect of technology shocks is clear: a contest is triggered once technology shocks shoot the cash flow variable $X_{t}$ up to the upper acquisition threshold. The effect of shocks to cash constraints is more subtle. According to a naive argument, cash constraints should have no effect, because even if a bidder is cash constrained, he can always pay the target the proportion of the stock of the combined firm. In the setting with bidders' private information about synergies, this naive argument is not valid, because a cash constrained bidder initiates a contest at a higher threshold than an unconstrained bidder. As a result, the change in economic environment that relaxes the bidders' cash constraints decreases the threshold on the level of cash flows at which each bidder initiates an acquisition and thereby sparks merger activity. ${ }^{19}$

A2. Companies acquired in cash generate higher total premiums (target+bidder) than companies acquired in stock.

Because bidders with intermediate to high synergies acquire targets in cash, the total premium in cash deals (as a percentage of the target's value) is higher.

\section{A3. For some parameterizations of the model, bidders pay higher takeover premiums to acquire com-}

contest is initiated over a finite time horizon $T$ is

$$
\begin{aligned}
& \mathbb{P}\left[\text { acquisition } \mid v_{1}, v_{2}, X_{t}, T\right]=\min \left\{1, N\left(\frac{-\log \frac{\min \left\{\bar{X}_{1}\left(v_{1}\right), \bar{X}_{2}\left(v_{2}\right)\right\}}{X_{t}}+\left(\mu-\sigma^{2} / 2\right) T}{\sigma \sqrt{T}}\right)\right. \\
& \left.+\exp \left\{\frac{2\left(\mu-\sigma^{2} / 2\right) \log \frac{\min \left\{\bar{X}_{1}\left(v_{1}\right), \bar{X}_{2}\left(v_{2}\right)\right\}}{X_{t}}}{\sigma^{2}}\right\} N\left(\frac{-\log \frac{\min \left\{\bar{X}_{1}\left(v_{1}\right), \bar{X}_{2}\left(v_{2}\right)\right\}}{X_{t}}-\left(\mu-\sigma^{2} / 2\right) T}{\sigma \sqrt{T}}\right)\right\} .
\end{aligned}
$$

Then, the conditional probability that a contest is initiated over a finite time horizon $T$ for any $v_{1}$ and $v_{2}$ is

$$
\mathbb{P}\left[\text { acquisition } \mid X_{t}, T\right]=\mathbb{E}_{v_{1}, v_{2}}\left[\mathbb{I}\left[v_{1}>v_{1}^{*}, v_{2}>v_{2}^{*}\right] \mathbb{P}\left[\text { acquisition } \mid v_{1}, v_{2}, X_{t}, T\right]\right],
$$

where $\mathbb{I}[\cdot]$ is the indicator function equal to one if the condition in brackets is satisfied and zero otherwise.

${ }^{19}$ Allowing cash constraints to evolve in time, e.g., switch from high to low level only strengthens this result. Intuitively, in states with low cash, bidders have extra incentives to delay the acquisition until their cash constraints are relaxed and acquisition in mostly cash is possible. 

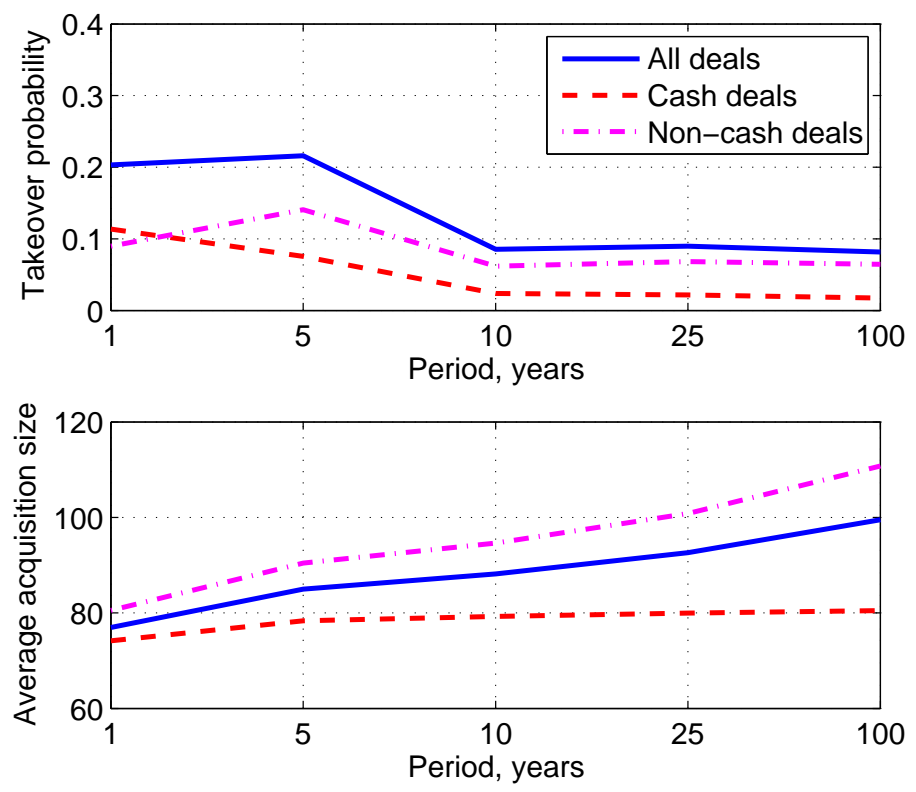

Figure 6: Takeover probability and average acquisition size in cash and non-cash deals. The figure corresponds to prediction A1. For the benchmark parametrization (Table I) and $C_{1}=125, C_{2}=0$, the top panel shows the frequency of takeovers initiated and completed in years $1,2-5,6-10,11-25$, and 26-100. The bottom panel shows the average acquisition size in deals completed by the end of years $1,5,10,25$, and 100. The starting value of the target is $X_{0}=\bar{X}_{1}(\bar{v})$. The solid line corresponds to all types of deals. The dashed (dash-dotted) line corresponds to cash (non-cash) deals.

panies in cash.

Despite the fact that bidders give away a smaller portion of synergies in cash acquisitions, they are the bidders with higher synergies. They give away a smaller portion of a larger pie. As a result, there exist parameterizations for which the effect of a pie increase dominates the effect of a smaller pie share and cash bidders on average pay higher takeover premiums (as a percentage of the target's value).

Figure 7 shows the average takeover premiums in cash and non-cash deals, both conditional on observing the highest bidder valuation and sample-wide unconditional, where the sample consists of takeover contests that differ only in valuations of participating bidders. As expected, the conditional takeover premiums are higher in non-cash deals for any value of highest valuation. However, in the case when both bidders have non-zero internal cash (Panels B and D), best deals are done exclusively in stock while worst deals are done exclusively in combinations on cash and stock which leads to an inverse relationship between the sample-wide unconditional average takeover premiums. This result is obtained without assuming either adverse selection about the bidders' assets or private information of the acquirer about his own firm as in the 
previous literature. It is the takeover timing-determined positive correlation between cash deals and high synergy deals that is responsible for the result.
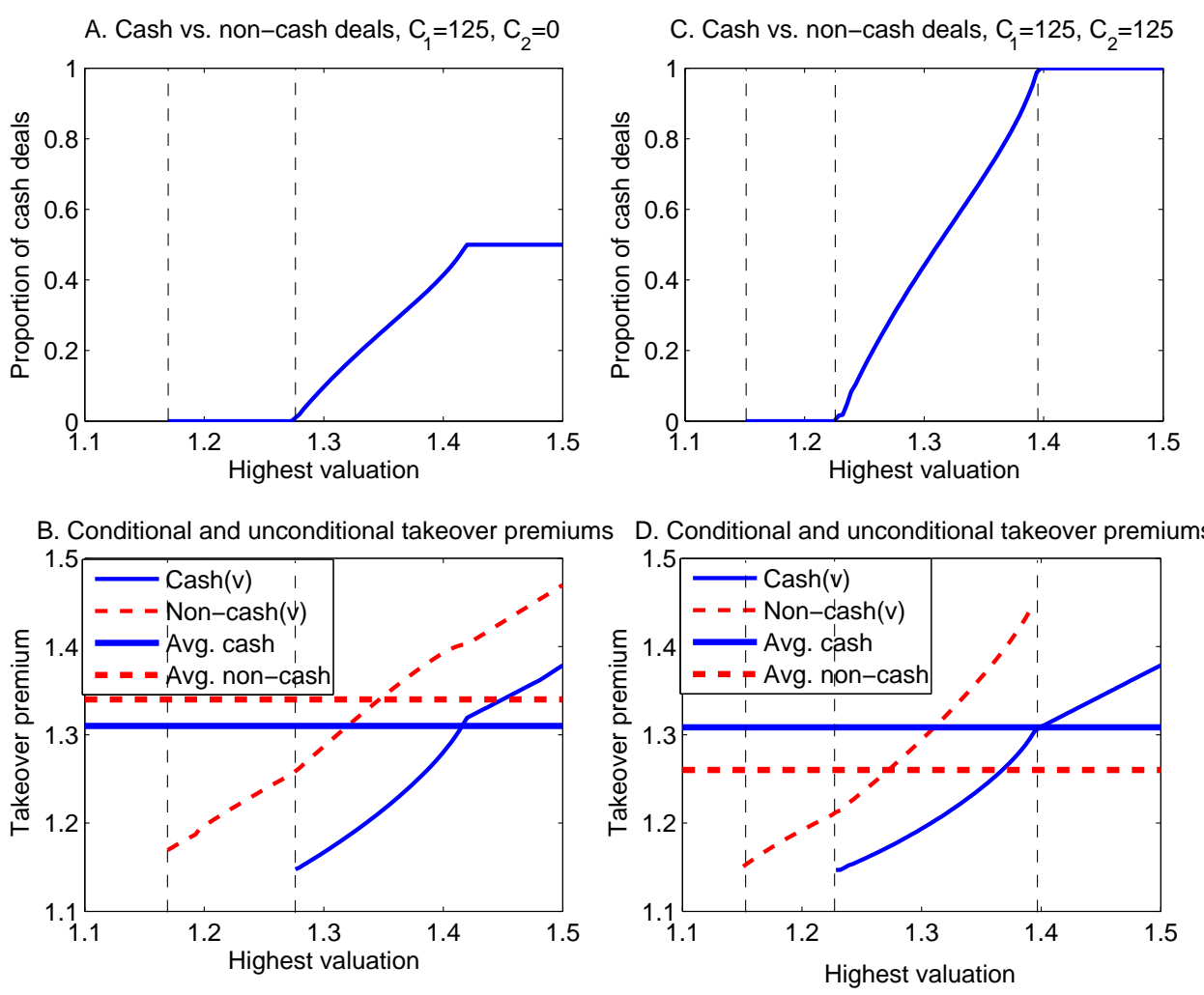

Figure 7: Conditional and unconditional takeover premiums in cash and non-cash deals. The figure corresponds to prediction A3. Panels $\mathrm{A}$ and $\mathrm{C}$ show, for the two cases: (i) $C_{1}=125, C_{2}=0$, (ii) $C_{1}=125, C_{2}=125$, the probability that a takeover contest is completed in cash as a function of the highest bidder valuation. Panels B and D show, for the same two cases, the average takeover premiums in cash and non-cash deals, both conditional on observing the highest bidder valuation (thick solid and dashed lines) and sample-wide unconditional (extra thick solid and dashed lines).

An empirical implication of A3 is that, if a good proxy of bidders' synergies can be found, then conditional on this proxy, takeover premiums in cash deals should be lower than those in noncash deals. A good proxy of synergies can be difficult to find; an alternative indirect approach is to estimate unobserved synergies from observed bids using a model of takeover auctions similar to ours. An implication of A3, then, is that conditional on the recovered synergies of the highest bidder, takeover premiums in cash deals should be lower than those in non-cash deals.

\section{A4. Stock bidders receive lower acquirer premiums than cash bidders.}

Not only do stock bidders give away a larger portion of synergies in acquisitions, but also they have lower synergies, so the two effects complement each other. 
A5. The target premium and the target revenue is higher when the bidder has an access to outside funding.

When the bidder with low synergies can use his equity to finance the deal, it will initiate the acquisition later, pay a larger proportion of its synergies to the target, which also means paying more in absolute terms.

These properties are consistent with existing empirical evidence. The first property is consistent with the evidence that takeovers paid in cash are for smaller firms than those partially or fully paid in stock (e.g., Betton, Eckbo, and Thorburn, 2008). The third property is consistent with a number of studies (e.g., Franks, Harris, and Mayer, 1988; Eckbo and Langohr, 1989) that historically, offer premiums were greater in all-cash offers, even controlling for the differential tax impact. The fourth property is consistent with the findings by Eckbo, Giammarino, and Heinkel (1990) and Berkovitch and Narayanan (1990) that the larger the cash portion of the deal, the higher are acquirer abnormal announcement returns. The second property is the combination of the two described above. Finally, the fifth property is consistent with the evidence that both the initial and final offer premiums are higher when the bidder is a public company and thus likely has an access to equity markets (Betton, Eckbo, and Thorburn, 2008).

\section{V.B Properties of Initiating and Winning Bidders}

B1. If the impact of an acquisition on the losing bidder is negative, bidders with sufficiently low synergies and cash constraints never initiate a contest.

As a result, there is a non-zero probability that neither cash-constrained bidder initiates a contest and a valuable target continues as a stand-alone. Figure 8, region (1) shows that for the benchmark model parametrization and cash constraints $C_{1}=125, C_{2}=0$, the probability that the target is never acquired is approximately $4 \%$. In the case of two stock bidders competing against each other, this probability is almost $9 \%$.

B2. In initiated contests, the distribution of participating bidders' valuations is determined endogenously and can be asymmetric.

This result holds true even if the unconditional distribution of synergies is the same for the bidders. Figure 8, left-most dashed line shows valuations of bidders 1 and $2, v$ and $w$, at which they initiate contest at the same threshold, $\bar{X}_{1}(v)=\bar{X}_{2}(w)$. In contests initiated by any bidder, the highest possible valuation of the more constrained bidder is higher than that of the less 
constrained bidder; the less constrained bidder also faces a stronger competitor on average. Interestingly, in the sample of takeovers that differ only in valuations of participating bidders, this result is reversed: because more constrained bidders are less likely to initiate takeover contests in the first place, their average valuation across all initiated contests is lower than that of less constrained bidders. Figure 9 shows how average valuations of the bidders with cash constraints $C_{1}=125, C_{2}=0$ change with respect to the parameters that have the strongest effect on the probability that a contest is never initiated: the value of the losing bidder, $P_{0}$ and the cash constraint of one of the bidders, specifically, $C_{1}$. Lower $P_{0}$ and $C_{1}$ correspond to a larger gap between $v_{1}^{*}$ and $v_{2}^{*}$ and result in a larger difference between average valuations in the sample of similar takeovers.

B3. Some initial bids of a less constrained bidder will be rejected in favor of a more constrained bidder. Under some parameterizations of the model, initial bids in cash have a smaller probability to be rejected compared to initial bids that include stock.

The second prediction is consistent with empirical evidence (Betton, Eckbo, and Thorburn, 2009) while the first prediction is novel. The two predictions might seem contradictory at first. However, a less constrained bidder and a bidder who completes the deal in cash are not equivalent. The latter bidder is more likely to have both high cash balances and high valuation so that he approaches the target while the deal can still be sealed in cash. For the benchmark parametrization and $C_{1}=125, C_{2}=0$, Figure 8, regions (2) and (4) show contests initiated by the less constrained bidder 1 in which the initial bidder bids in combinations of cash and stock. Region (4) shows contests in which such bidder loses to bidder 2 who bids in stock. Region (6) shows contests initiated by bidder 2 who wins in stock. The conditional probability of the initiating non-cash bidder losing the contest is the area of region (4) divided by the combined areas of regions (2), (4), and (6) and is equal to approximately 10\%. In contrast, regions (3) and (5) show contests initiated by the less constrained bidder 1 in which the initial bidder bids in cash. Region (5) shows contests in which such bidder loses to bidder 2 who bids in stock. The conditional provability of the initiating cash bidder losing the contest is the area of region (5) divided by the combined area of regions (3) and (5) and is equal to approximately $2.6 \%$. Hence, for a given parametrization, cash bids by the initiating bidder indeed have a smaller probability to be rejected compared to non-cash bids. It is easy to construct an example in which the opposite is true: take $C_{1} \rightarrow \infty, C_{2}=0$. In this case, there is zero correlation between cash bids and cash 
bidder valuations and only initial cash but not stock bids can be rejected.

\section{V.C Target's Preference for Cash versus Stock Bids}

A famous result in the static security design literature (see, e.g., Hansen, 1985, and DeMarzo, Kremer, and Skrzypacz, 2005) is that contests in stock dominate contests in cash in terms of the expected revenues of the seller. As a result, if in a static setting the target can commit to accept only stock bids, she will do so. However, practical cases of such commitment in takeover contests are rare. An interesting question is to study whether the target would have incentives to commit to accept only stock bids in a dynamic setting, when bidders can time an acquisition. In this paper, we do not aim to provide a rigorous answer to this question. One of the complications that can arise is that the target, upon learning about bidder valuations from their initiation (and non-initiation) decisions, can change the preferred security design of the takeover contest dynamically. Instead, to provide a flavor of the more general case, we consider a simpler setting in which the target has to commit to the security design at time zero. ${ }^{20}$ We also focus on the case in which both bidders are exogenously unconstrained: $C_{1} \rightarrow \infty, C_{2} \rightarrow \infty$.

Figure 10 shows the ratio of present values of target revenues in cash and stock contests as a function of $\mu, \sigma$, and $r$. For realistic parameters, the target prefers not to commit to restricting bids to stock. When $\mu$ and $\sigma$ are well above realistic parameters (or $r$ is very low), contests in stock start to dominate contests in cash in terms of target revenue. Intuitively, if a target has a higher growth rate or higher volatility of assets (or interest rate is lower), the difference between initiation thresholds of cash and stock bidders is passed quicker (or affects the present value of target revenues less). As a result, the effect of extra delay is less important for the present value of high-growth targets, which leads to their preference for battles in stock. ${ }^{21}$

This result suggests that in a dynamic setting, most targets (including targets with "standard" characteristics that are similar to an average COMPUSTAT firm) can have aligned incentives with the bidders: both the bidders and the target can prefer cash deals. This is in line with the observation that there are very few (if any) practical cases in which the target attempts to restrict the type of

\footnotetext{
${ }^{20}$ The results remain the same for any $X_{0}$ below the lowest initiation threshold of the bidders: expected target revenue takes the form $\alpha+\gamma_{j} X_{0}^{\beta}$, where $j \in\{c, s\}$ corresponds to the case of cash and stock bids. This also means that as long as $X_{t}$ stays below the lowest initiation threshold, the target does not have incentives to attempt and change the security design in this region.

${ }^{21}$ If the target can choose whether to restrict the type of bids at any point of time, learning about bidder valuations from $X_{t}$ strengthens her incentives to commit to restricting bids. This is because, as the support of possible bidder valuations shrinks, stock bids extract an increasingly higher proportion of revenues from the bidders.
} 


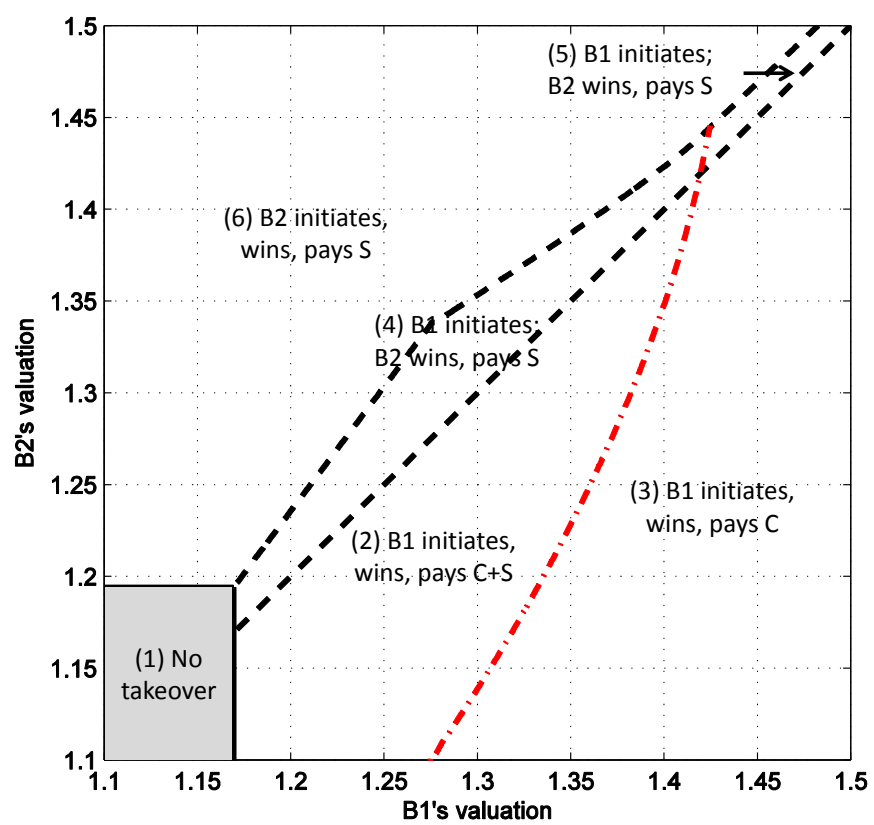

Figure 8: Initiation, acquisition and means of payment in takeover contests with cash constrained bidders. For the benchmark parametrization (Table I) and cash constraints of bidders 1 and 2 equal to $C_{1}=125, C_{2}=0$, the figure shows regions of valuations for which bidders initiate and win takeover contests, as well as the resulting type of the deal (cash, cash and stock, stock). The dash-dotted line separates the cases in which bidder 1 makes cash and non-cash final bids.
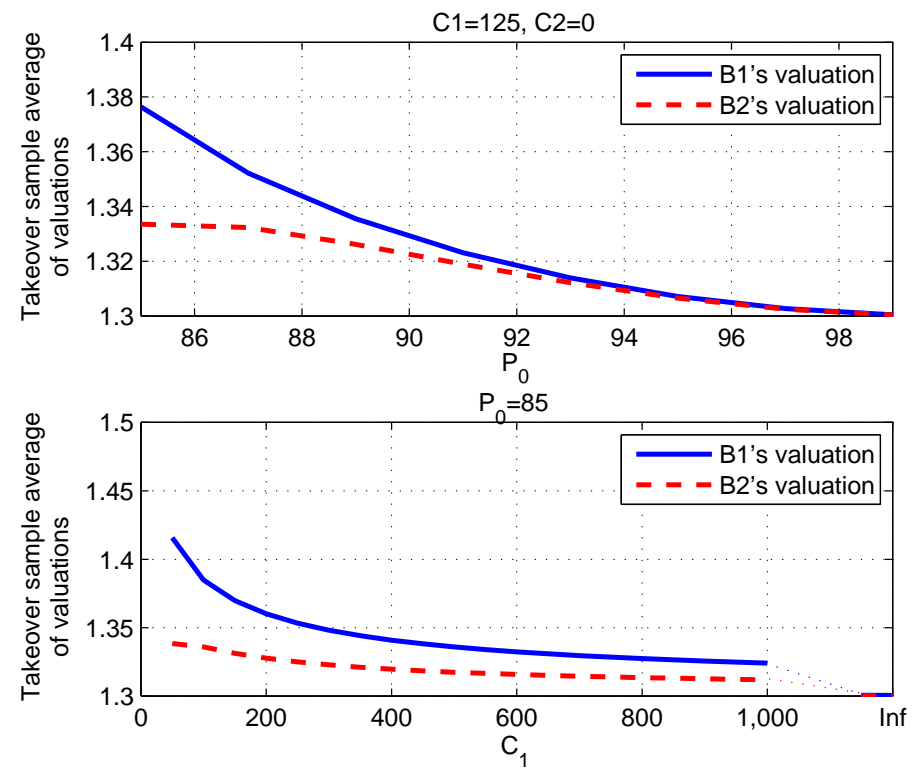

Figure 9: Average valuations of cash constrained bidders in initiated contests. The figure shows average valuations of cash constrained bidders for the benchmark parametrization (Table I) as a function of (i) the value of the losing bidder, $P_{0}$, assuming cash constraints $C_{1}=125, C_{2}=0$, and (ii) cash constraint of bidder $1, C_{1}$, assuming $C_{2}=0$ and $P_{0}=85$. The solid (dashed) line is the average valuation of bidder $1(2)$. 

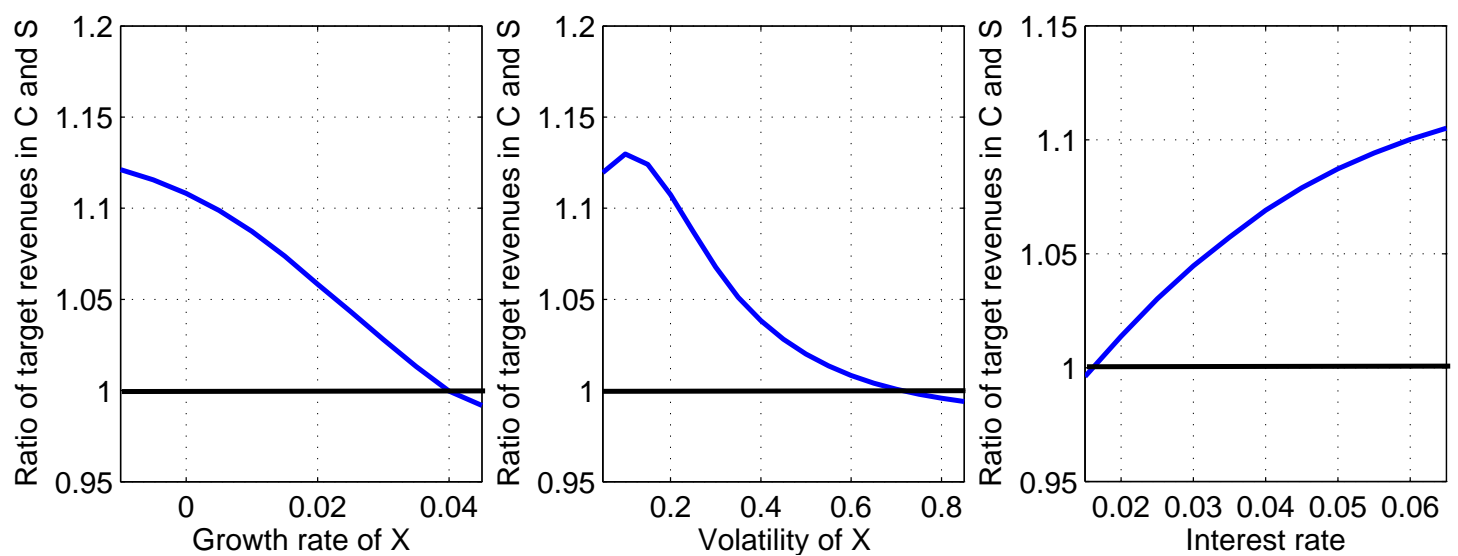

Figure 10: The ratio of the target revenue (present value) from contests in cash and in stock. For the benchmark parametrization (Table I), the figure shows the ratio of present values of target revenues in cash and stock deals as a function of (i) the growth rate of the target's assets, $\mu$, (ii) the volatility of the target's assets, $\sigma$, (iii) the interest rate $r$.

bids. However, a small fraction of firms with either high growth or high volatility of assets can have misaligned incentives with the bidders. If there is any evidence regarding the target's ability to restrict the type of bids in takeover contests, it is likely to be found among high- $\mu$, high- $\sigma$ targets. ${ }^{22}$

\section{Concluding Remarks}

This paper presents a theoretical analysis of the timing of acquisitions, takeover premiums, and means of payment in the setting in which firms' fortunes and ability to pay cash are affected by the technological change and cash constraints. Optimal choices of each bidder and, in turn, takeover outcomes are affected not only by synergies of this bidder with the target but also by cash constraints of both the bidder and his competitors. The results of our general model are consistent with a wide variety of cross-sectional and time-series empirical findings. In particular, they provide an explanation, alternative to Fishman (1989), why cash deals feature higher average takeover premiums than non-cash cash deals. In our model, high-synergy bidders approach their targets earlier, before they grow large enough to make bidders' cash constraints binding, and thus have enough cash to finalize the deal. We also propose several novel testable predictions that relate the timing of an acquisition and its outcomes to key characteristics of competing bidders. Importantly, these predictions explicitly recognize the effect of private information and self-selection on decision making.

\footnotetext{
${ }^{22}$ In contests for growth targets and targets from hi-tech industries, it is common that target managers are major stockholders in their company and have much control over its decision making, including the ability to negotiate terms of a potential takeover. In many cases, they eventually become large stockholders of the combined company, which is consistent with our result.
} 
A potential direction of future research is to understand targets' motives to initiate takeover contests by themselves, which is common in practice. In our setting, because a target cannot realistically make a take-it-or-leave-it preemptive offer to sell herself, the bidders will always delay initiation until it is optimal for them to approach the target. Thus, all deals will be bidder-initiated. However, in settings when initiation discloses commonly useful information about the value of the target, bidders can be unwilling to approach the target as this can result in a loss of informational advantage. Here, a preemptive offer by the target can be to both sides' benefit. Another direction of future research is to test predictions of our model. In particular, it seems important to quantify the relative importance of the two bidder self-selection stories on takeover outcomes: ours and that of Fishman (1989).

\section{Appendix A Proofs}

Proof of Proposition 1. Taking the first-order condition (5) and dividing both sides by $X_{0}^{\beta}$ yields

$$
\begin{aligned}
0= & -\beta \frac{1}{\bar{X}^{\beta+1}} \int_{\underline{v}}^{\bar{X}_{c}^{-1}(\bar{X})}(\bar{X} \max \{v-w, 0\}-\Delta) d F(w) \\
& +\frac{1}{\bar{X}^{\beta}} \int_{\underline{v}}^{\bar{X}_{c}^{-1}(\bar{X})} \max \{v-w, 0\} d F(w)
\end{aligned}
$$

In equilibrium, the maximum is reached at $\bar{X}_{c}(v)$. Plugging in and multiplying both sides by $\bar{X}_{c}(v)^{\beta+1}$, we get

$$
\bar{X}_{c}(v)(\beta-1) \int_{\underline{v}}^{v}(v-w) d F(w)=\beta \Delta F(v) .
$$

Hence,

$$
\bar{X}_{c}(v)=\frac{\beta}{\beta-1} \frac{\Delta}{v-\mathbb{E}[w \mid w \leq v]} .
$$

By assumption, $v-\mathbb{E}[w \mid w \leq v]$ is increasing in $v$. Therefore, $\bar{X}_{c}(v)$ is indeed decreasing in $v$.

Proof of Proposition 2. Taking the first-order condition (11) and dividing both sides by $X_{0}^{\beta}$ yields

$$
\begin{aligned}
0= & -\beta \frac{1}{\bar{X}^{\beta+1}} \int_{\underline{v}}^{\bar{X}_{s}^{-1}(\bar{X})}\left(\Pi_{o} \frac{\Pi_{b}+\bar{X} v}{\Pi_{b}+\bar{X} w}-\Pi_{b}\right) d F(w) \\
& +\frac{1}{\bar{X}^{\beta}} \int_{\underline{v}}^{\bar{X}_{s}^{-1}(\bar{X})} \Pi_{o}\left[\frac{\Pi_{b}+\bar{X} v}{\Pi_{b}+\bar{X} w}\right]^{\prime} d F(w) .
\end{aligned}
$$

The derivative is equal to

$$
\left[\frac{\Pi_{b}+\bar{X} v}{\Pi_{b}+\bar{X} w}\right]^{\prime}=\frac{(v-w) \Pi_{b}}{\left(\Pi_{b}+\bar{X} w\right)^{2}}
$$


Plugging it into (A4), dividing by $F(v)$, and using the fact that in equilibrium the maximum is reached at $\bar{X}_{s}(v)$, we obtain

$$
\begin{aligned}
0= & -\beta \Pi_{o} \mathbb{E}\left[\frac{\Pi_{b}+v \bar{X}_{s}(v)}{\Pi_{b}+w \bar{X}_{s}(v)} \mid w \leq v\right]+\beta \Pi_{b} \\
& +\Pi_{o} \Pi_{b} \mathbb{E}\left[\frac{(v-w) \bar{X}_{s}(v)}{\left(\Pi_{b}+w \bar{X}_{s}(v)\right)} \mid w \leq v\right] .
\end{aligned}
$$

Rewriting, we obtain (12).

Proof of Proposition 3. We need to compare

$$
\mathbb{E}[v-w \mid w \leq v] \text { and } \mathbb{E}\left[\frac{\Pi_{o}\left(\Pi_{b}+\frac{\beta}{\beta-1} w \bar{X}\right)}{\left(\Pi_{b}+w \bar{X}\right)^{2}}(v-w) \mid w \leq v\right]
$$

Consider the following difference:

$$
\begin{aligned}
1-\frac{\Pi_{o}\left(\Pi_{b}+\frac{\beta}{\beta-1} w \bar{X}\right)}{\left(\Pi_{b}+w \bar{X}\right)^{2}} & =\frac{\Pi_{b}^{2}+2 \Pi_{b} w \bar{X}+w^{2} \bar{X}^{2}-\Pi_{o} \Pi_{b}-\frac{\beta}{\beta-1} \Pi_{o} w \bar{X}}{\left(\Pi_{b}+w \bar{X}\right)^{2}} \\
& =\frac{\Pi_{b}\left(\Pi_{b}-\Pi_{o}\right)+\left(2 \Pi_{b}-\frac{\beta}{\beta-1} \Pi_{o}\right) \bar{X}+w^{2} \bar{X}^{2}}{\left(\Pi_{b}+w \bar{X}\right)^{2}} .
\end{aligned}
$$

The first term in the numerator is positive because $\Pi_{b}>\Pi_{o}$. The second term in the numerator is positive because of (16). Therefore, (A8) is positive for all $w$ and $\bar{X}$. Consequently,

$$
\mathbb{E}[v-w \mid w \leq v]>\mathbb{E}\left[\frac{\Pi_{o}\left(\Pi_{b}+\frac{\beta}{\beta-1} w \bar{X}\right)}{\left(\Pi_{b}+w \bar{X}\right)^{2}}(v-w) \mid w \leq v\right] .
$$

Because of this and monotonicity of the left-hand side of (12) with respect to $\bar{X}$, the unique solution of (12), $v>v^{*}$ is higher than the unique solution of $(6)$.

Proof of Proposition 4. First, we maximize (20) with respect to threshold $\bar{X}$. Analogously to the proof of proposition 1, we obtain (21). Second, we maximize (22) with respect to threshold $\bar{X}$ :

$$
\begin{aligned}
0= & -\frac{\beta}{\bar{X}^{\beta+1}} \int_{\underline{v}}^{\bar{X}_{1}^{-1}(\bar{X})}\left(\Pi_{o} \frac{(v-w) \bar{X}}{\Pi_{b}+w \bar{X}}-\Delta\right) f(w) d w \\
& +\frac{1}{\bar{X}^{\beta}} \int_{\underline{v}}^{\bar{X}_{1}^{-1}(\bar{X})} \Pi_{o}\left[\frac{(v-w) \bar{X}}{\Pi_{b}+w \bar{X}}\right]^{\prime} f(w) d w .
\end{aligned}
$$


Equivalently,

$$
\begin{aligned}
0= & -\beta \int_{\underline{v}}^{\bar{X}_{1}^{-1}(\bar{X})} \Pi_{o} \frac{(v-w) \bar{X}}{\Pi_{b}+w \bar{X}} f(w) d w+\beta \Delta F\left(\bar{X}_{1}^{-1}(\bar{X})\right) \\
& +\bar{X} \int_{\underline{v}}^{\bar{X}_{1}^{-1}(\bar{X})} \Pi_{o} \frac{(v-w) \Pi_{b}}{\left(\Pi_{b}+w \bar{X}\right)^{2}} f(w) d w .
\end{aligned}
$$

Dividing by $F\left(\bar{X}_{1}^{-1}(\bar{X})\right)$ :

$$
\begin{gathered}
0=-\beta \Pi_{o} \mathbb{E}\left[\frac{(v-w) \bar{X}}{\Pi_{b}+w \bar{X}} \mid w \leq \bar{X}_{1}^{-1}(\bar{X})\right]+\beta \Delta \\
+\Pi_{o} \mathbb{E}\left[\frac{(v-w) \bar{X} \Pi_{b}}{\left(\Pi_{b}+w \bar{X}\right)^{2}} \mid w \leq \bar{X}_{1}^{-1}(\bar{X})\right] .
\end{gathered}
$$

Equivalently,

$$
\mathbb{E}\left[\beta \frac{v-w}{\Pi_{b}+w \bar{X}}-\Pi_{b} \frac{v-w}{\left(\Pi_{b}+w \bar{X}\right)^{2}} \mid w \leq \bar{X}_{1}^{-1}(\bar{X})\right] \bar{X}=\beta \frac{\Delta}{\Pi_{o}} .
$$

Rewriting yields (23). Finally, we need to determine the synergy parameter $v^{*}$ such that bidder 2 never approaches the target if $v \leq v^{*}$. Consider $\bar{X} \rightarrow \infty$. Because $\bar{X}_{1}(\underline{v})$ is finite as $\underline{v}>1, \bar{X}_{1}^{-1}(\bar{X})=\underline{v}$. Therefore, the left-hand side of (A13) is

$$
\mathbb{E}\left[\beta \frac{v-w}{w} \mid w \leq \underline{v}\right]=\beta \frac{v-\underline{v}}{\underline{v}}
$$

Point $v^{*}$ is such that

$$
\beta \frac{v^{*}-\underline{v}}{\underline{v}}=\beta \frac{\Delta}{\Pi_{O}},
$$

which yields

$$
v^{*}=\frac{\Pi_{b}}{\Pi_{o}} \underline{v}
$$

Proof of Proposition 5. Proposition 3 establishes that $\bar{X}_{s}(v)>\bar{X}_{c}(v)$ for all $v$ when $\frac{\beta}{\beta-1}<2 \frac{\Pi_{b}}{\Pi_{o}}$. Suppose that $\bar{X}_{1}(\tilde{v})=\bar{X}_{2}(\tilde{v})$ for some $\tilde{v}$. Then, $\Psi(\tilde{v})=1, \Omega(\tilde{v})=v$. As a result, $\bar{X}_{1}(\tilde{v})=\bar{X}_{c}(\tilde{v}) ; \bar{X}_{2}(\tilde{v})=$ $\bar{X}_{s}(\tilde{v})$ and, under the assumption $\bar{X}_{1}(\tilde{v})=\bar{X}_{2}(\tilde{v})$, all four strategies have to be equal at $\tilde{v}$ - a contradiction with the result of Proposition 3. Hence $\bar{X}_{2}$ and $\bar{X}_{1}$ cannot cross.

Assume that $\bar{X}_{1}(\hat{v})>\bar{X}_{2}(\hat{v})$ for some $\hat{v}$. From Proposition 4 , as $v \downarrow v^{*}, \bar{X}_{2}(v) \rightarrow \infty$ while $\bar{X}_{1}(v)$ remains finite. Hence, there exists $\epsilon>0$ such that $\bar{X}_{2}\left(v^{*}+\epsilon\right)>\bar{X}_{1}\left(v^{*}+\epsilon\right)$. This, together with the assumption $\bar{X}_{1}(\hat{v})>\bar{X}_{2}(\hat{v})$ and continuity of both $\bar{X}_{1}(v)$ and $\bar{X}_{2}(v)$ in $v$, implies that $\bar{X}_{1}(\tilde{v})=\bar{X}_{2}(\tilde{v})$ for some $\tilde{v} \in\left(v^{*}+\epsilon, \hat{v}\right)$. By earlier proof, however, $\bar{X}_{2}$ and $\bar{X}_{1}$ cannot cross. Hence, $\bar{X}_{2}(v)>\bar{X}_{1}(v)$ for all $v$.

The final step is to show that $\bar{X}_{s}(v)>\bar{X}_{2}(v)$ and $\bar{X}_{1}(v)>\bar{X}_{2}(v)$ for all $v$. Both inequalities follow from 
the fact that, when $\bar{X}_{2}(v)>\bar{X}_{1}(v)$ for all $v$, then $\Psi(v)>1$ and $\Omega(v)<v$.

Proof of Proposition 6. The first-order condition of (28) is

$$
\begin{aligned}
0= & -\frac{\beta}{\bar{X}^{\beta+1}} \int_{\underline{v}}^{\bar{X}_{-i}^{-1}(\bar{X})}\left(\min \left\{\frac{\Pi_{o}+C_{i}}{\Pi_{b}+w \bar{X}}, 1\right\} \bar{X} \max \{v-w, 0\}-\Delta\right) d F(w) \\
& +\frac{1}{\bar{X}^{\beta}} \int_{\underline{v}}^{\bar{X}_{-i}^{-1}(\bar{X})}\left[\min \left\{\frac{\Pi_{o}+C_{i}}{\Pi_{b}+w \bar{X}}, 1\right\} \bar{X} \max \{v-w, 0\}\right]^{\prime} d F(w) .
\end{aligned}
$$

Equivalently,

$$
\begin{aligned}
0= & -\beta \int_{\underline{v}}^{\bar{X}_{-i}^{-1}(\bar{X})}\left(\min \left\{\frac{\Pi_{o}+C_{i}}{\Pi_{b}+w \bar{X}}, 1\right\} \bar{X} \max \{v-w, 0\}\right) d F(w) \\
& +\beta \Delta F\left(\bar{X}_{-i}^{-1}(\bar{X})\right)+\bar{X} \int_{\underline{v}}^{\bar{X}_{-i}^{-1}(\bar{X})}\left[\min \left\{\frac{\Pi_{o}+C_{i}}{\Pi_{b}+w \bar{X}}, 1\right\} \bar{X} \max \{v-w, 0\}\right]^{\prime} d F(w) .
\end{aligned}
$$

Applying the equilibrium condition that the maximum is reached at $\bar{X}_{i}(v)$ and dividing by $F(\Omega(v))$ yields

$$
\begin{aligned}
& \mathbb{E}\left[\beta \min \left\{\frac{\Pi_{o}+C_{i}}{\Pi_{b}+w \bar{X}_{i}(v)}, 1\right\}(v-w) \mid w \leq \Omega(v)\right] \bar{X}_{i}(v) \\
& -\mathbb{E}\left[\left[\min \left\{\frac{\Pi_{o}+C_{i}}{\Pi_{b}+w \bar{X}_{i}(v)}, 1\right\}(v-w) \bar{X}_{i}(v)\right]^{\prime} \mid w \leq \Omega(v)\right] \bar{X}_{i}(v) \\
= & \beta \Delta \Psi(v) .
\end{aligned}
$$

Let us decompose this expression into two intervals:

- if $w<\left(C_{i}-\Delta\right) / \bar{X}_{i}(v)$, then the expression under the expectation operator is

$$
\beta(v-w)-\left[(v-w) \bar{X}_{i}(v)\right]^{\prime}=(\beta-1)(v-w) ;
$$

- if $w>\left(C_{i}-\Delta\right) / \bar{X}_{i}(v)$, then the expression under the expectation operator is

$$
\begin{aligned}
&\left(\Pi_{o}+C_{i}\right)\left(\frac{\beta(v-w)}{\Pi_{b}+w \bar{X}_{i}(v)}-\left[\frac{(v-w) \bar{X}_{i}(v)}{\Pi_{b}+w \bar{X}_{i}(v)}\right]^{\prime}\right) \\
&=\left(\Pi_{o}+C_{i}\right)\left(\frac{\beta(v-w)}{\Pi_{b}+w \bar{X}_{i}(v)}-\frac{(v-w) \Pi_{b}}{\left(\Pi_{b}+w \bar{X}_{i}(v)\right)^{2}}\right) \\
&=(\beta-1) \frac{\left(\Pi_{o}+C_{i}\right)(v-w)}{\Pi_{b}+w \bar{X}_{i}(v)}+(\beta-1) \frac{\left(\Pi_{o}+C_{i}\right)(v-w)}{\Pi_{b}+w \bar{X}_{i}(v)} \frac{1}{\beta-1} w \bar{X}_{i}(v) \\
& \Pi_{b}+w \bar{X}_{i}(v)
\end{aligned} .
$$

Hence, we can rewrite (A19) as (29). 
Similar to Section II.B, equations (29) do not have solutions for low enough $v$. Let $v_{i}^{*}$ be such that $\lim _{v \rightarrow v_{i}^{*}} \bar{X}_{i}(v)=\infty$. Rewriting $(29)$ at this point yields

$$
\mathbb{E}\left[\frac{v_{i}^{*}-w}{w} \mid w \leq \Omega\left(v_{i}^{*}\right)\right]=\frac{\Delta \Psi\left(v_{i}^{*}\right)}{\Pi_{o}+C_{i}}
$$

In the case of symmetric cash constraints, $C_{1}=C_{2}=C$ and $v_{1}^{*}=v_{2}^{*}=v^{*}$, given by

$$
\mathbb{E}\left[\frac{v^{*}-w}{w} \mid w \leq v^{*}\right]=\frac{\Delta}{\Pi_{o}+C_{i}}
$$

It is easy to see that in the special cases of $C \rightarrow \infty$ and $C=0$ and, we obtain $\underline{v}$ and $v^{*}$ from Section II.B, respectively.

Proof of Proposition 7. Let $v_{i}(x):=\bar{X}_{i}^{-1}(x)$ be the type of bidder $i \in\{1,2\}$ that approaches the target at threshold $x$. We can re-write (A19) in terms of $v_{1}(x)$ and $v_{2}(x)$ :

$$
\begin{aligned}
& \mathbb{E}\left[\left(\beta \min \left\{\frac{\Pi_{o}+C_{i}}{\Pi_{b}+w x}, 1\right\}-\left[\min \left\{\frac{\Pi_{o}+C_{i}}{\Pi_{b}+w x}, 1\right\} x\right]^{\prime}\right)\left(v_{i}(x)-w\right) \mid w \leq \min _{j \in\{1,2\}} v_{j}(x)\right] x \\
& -\beta \Delta \frac{F\left(\max _{j \in\{1,2\}} v_{j}(x)\right)}{F\left(v_{i}(x)\right)}=0 .
\end{aligned}
$$

Denote the left-hand side by $\delta_{i}\left(x, v_{i}, v_{-i}, \Theta\right)$, where $\Theta$ is the set of comparative statics parameters, and where the suppress the dependence of $v_{i}$ and $v_{-i}$ on $x$ for notational simplicity. The system of equations is thus $\delta_{i}\left(x, v_{i}(x), v_{-i}(x), \Theta\right)=0, i \in\{1,2\}$.

The following auxiliary result will be useful to prove the proposition.

Lemma 1. $\frac{\partial \delta_{1}}{\partial v_{1}} \frac{\partial \delta_{2}}{\partial v_{2}}-\frac{\partial \delta_{1}}{\partial v_{2}} \frac{\partial \delta_{2}}{\partial v_{1}}>0$ at the equilibrium.

Proof of Lemma 1. Taking the full derivatives of these equations around the solution $x$ everywhere where the derivatives exist yields

$$
\begin{aligned}
& \frac{\partial \delta_{1}}{\partial x}+\frac{\partial \delta_{1}}{\partial v_{1}} v_{1}^{\prime}(x)+\frac{\partial \delta_{1}}{\partial v_{2}} v_{2}^{\prime}(x)=0 \\
& \frac{\partial \delta_{2}}{\partial x}+\frac{\partial \delta_{2}}{\partial v_{2}} v_{2}^{\prime}(x)+\frac{\partial \delta_{2}}{\partial v_{1}} v_{1}^{\prime}(x)=0 .
\end{aligned}
$$

Combining these equations, we obtain:

$$
\left(\frac{\partial \delta_{1}}{\partial v_{1}} \frac{\partial \delta_{2}}{\partial v_{2}}-\frac{\partial \delta_{1}}{\partial v_{2}} \frac{\partial \delta_{2}}{\partial v_{1}}\right) v_{i}^{\prime}(x)=\frac{\partial \delta_{i}}{\partial v_{-i}} \frac{\partial \delta_{-i}}{\partial x}-\frac{\partial \delta_{i}}{\partial x} \frac{\partial \delta_{-i}}{\partial v_{-i}}
$$

where $i \in\{1,2\}$. Because $\bar{X}_{i}(v)$ maximizes the bidder's value function and not minimizes it, $\frac{\partial \delta_{i}\left(x, v_{i}, v_{-i}, \Theta\right)}{\partial x}>0$, 
$i \in\{1,2\} .{ }^{23}$

Fix $x$. Without loss of generality, assume $v_{i}(x) \geq v_{-i}(x)$. Then, $\min _{j \in\{1,2\}} v_{j}(x)=v_{-i}(x)$ and $\max _{j \in\{1,2\}} v_{j}(x)=v_{i}(x)$. First, consider bidder $i$. In the neighborhood of the equilibrium,

$$
\delta_{i}\left(x, v_{i}, v_{-i}, \Theta\right)=\mathbb{E}\left[\left(\beta \min \left\{\frac{\Pi_{o}+C_{i}}{\Pi_{b}+w x}, 1\right\}-\left[\min \left\{\frac{\Pi_{o}+C_{i}}{\Pi_{b}+w x}, 1\right\} x\right]^{\prime}\right)\left(v_{i}-w\right) x-\beta \Delta \mid w \leq v_{-i}\right] .
$$

Hence,

$$
\frac{\partial \delta_{i}}{\partial v_{i}}=\mathbb{E}\left[\left(\beta \min \left\{\frac{\Pi_{o}+C_{i}}{\Pi_{b}+w x}, 1\right\}-\left[\min \left\{\frac{\Pi_{o}+C_{i}}{\Pi_{b}+w x}, 1\right\} x\right]^{\prime}\right) \mid w \leq v_{-i}\right] x>0
$$

Let

$$
d_{i}\left(x, v_{i}, w, \Theta\right) \equiv\left(\beta \min \left\{\frac{\Pi_{o}+C_{i}}{\Pi_{b}+w x}, 1\right\}-\left[\min \left\{\frac{\Pi_{o}+C_{i}}{\Pi_{b}+w x}, 1\right\} x\right]^{\prime}\right)\left(v_{i}-w\right) x-\beta \Delta
$$

be the integrand under the expectation sign in $\delta_{i}\left(x, v_{i}, v_{-i}, \Theta\right)$. Let us show that $d_{i}\left(x, v_{i}(x), v_{-i}(x), \Theta\right)<0$. Consider $d_{i}\left(x, v_{i}, w, \Theta\right)$ as a function of $w$. Clearly, it is strictly decreasing in $w$ in the range $w<\left(C_{i}-\Delta\right) / x$, as $d_{i}\left(x, v_{i}, w, \Theta\right)=(\beta-1)\left(v_{i}-w\right)$. Consider $w>\left(C_{i}-\Delta\right) / x$. Differentiating with respect to $w$,

$$
\begin{aligned}
\frac{\partial d_{i}}{\partial w}\left(x, v_{i}, w, \Theta\right) & =-\frac{\left(\Pi_{o}+C_{i}\right) x}{\left(\Pi_{b}+w x\right)^{2}}\left(\left(\Pi_{b}+x v_{i}\right)\left(\beta-\frac{\Pi_{b}}{\Pi_{b}+w x}\right)-\frac{\Pi_{b} x\left(v_{i}-w\right)}{\Pi_{b}+w x}\right) \\
& <-\frac{\left(\Pi_{o}+C_{i}\right) x}{\left(\Pi_{b}+w x\right)^{2}}\left(\left(\Pi_{b}+x v_{i}\right) \frac{\Pi_{b}+2 w x}{\Pi_{b}+w x}-\frac{\Pi_{b} x\left(v_{i}-w\right)}{\Pi_{b}+w x}\right) \\
& =-\frac{\left(\Pi_{o}+C_{i}\right) x}{\left(\Pi_{b}+w x\right)^{3}}\left(\Pi_{b}^{2}+3 w x \Pi_{b}+2 w x^{2} v_{i}\right)<0,
\end{aligned}
$$

where the intermediate inequality follows, because $\frac{\beta}{\beta-1}<2 \frac{\Pi_{b}}{\Pi_{o}}$ implies $\beta>2$. Because either $C_{i}<\Delta$ or $C_{i} \rightarrow \infty, d_{i}\left(x, v_{i}, w, \Theta\right)$ never jumps from one region to the other as $w$ changes. Therefore, $d_{i}\left(x, v_{i}, w, \Theta\right)$ is strictly decreasing in $w$. Thus, $\mathbb{E}\left[d_{i}\left(x, v_{i}(x), w, \Theta\right) \mid w \leq v_{-i}(x)\right]=0$ implies $d_{i}\left(x, v_{i}(x), v_{-i}(x), \Theta\right)<0$. Therefore,

$$
\begin{aligned}
\frac{\partial \delta_{i}}{\partial v_{-i}} & =\left(d_{i}\left(x, v_{i}, v_{-i}, \Theta\right)-\delta_{i}\left(x, v_{i}, v_{-i}, \Theta\right)\right) \frac{f\left(v_{-i}\right)}{F\left(v_{-i}\right)} \\
& =d_{i}\left(x, v_{i}, v_{-i}, \Theta\right) \frac{f\left(v_{-i}\right)}{F\left(v_{-i}\right)}<0 .
\end{aligned}
$$

Second, consider bidder $-i$. In the neighborhood of the equilibrium,

$$
\begin{aligned}
& \delta_{-i}\left(x, v_{-i}, v_{i}, \Theta\right) \\
= & \mathbb{E}\left[\left(\beta \min \left\{\frac{\Pi_{o}+C_{-i}}{\Pi_{b}+w x}, 1\right\}-\left[\min \left\{\frac{\Pi_{o}+C_{-i}}{\Pi_{b}+w x}, 1\right\} x\right]^{\prime}\right)\left(v_{-i}-w\right) x \mid w \leq v_{-i}\right]-\beta \Delta \frac{F\left(v_{i}\right)}{F\left(v_{-i}\right)} .
\end{aligned}
$$

\footnotetext{
${ }^{23}$ This follows from the second derivative of the bidder's value function with respect to the threshold at $\bar{X}_{i}(v)$ being $-\frac{\partial \delta\left(\bar{X}_{i}(v), v, v_{-i}\left(\bar{X}_{i}(v)\right), \Theta\right)}{\partial x} / \bar{X}(v)^{\beta+1}$. It must be negative for any $v$.
} 
Hence,

$$
\frac{\partial \delta_{-i}}{\partial v_{i}}=-\beta \Delta \frac{f\left(v_{i}\right)}{F\left(v_{-i}\right)}<0 \text { for all } v_{i} \in[\underline{v}, \bar{v}]
$$

$$
\begin{aligned}
\frac{\partial \delta_{-i}}{\partial v_{-i}} & =\int_{\underline{v}}^{v_{-i}}\left(\beta \min \left\{\frac{\Pi_{o}+C_{-i}}{\Pi_{b}+w x}, 1\right\}-\left[\min \left\{\frac{\Pi_{o}+C_{-i}}{\Pi_{b}+w x}, 1\right\} x\right]^{\prime}\right) x \frac{d F(w)}{F\left(v_{-i}\right)}-\frac{f\left(v_{-i}\right)}{F\left(v_{-i}\right)} \delta_{-i}\left(x, v_{-i}, v_{i}, \Theta\right) \\
& =\int_{\underline{v}}^{v_{-i}}\left(\beta \min \left\{\frac{\Pi_{o}+C_{-i}}{\Pi_{b}+w x}, 1\right\}-\left[\min \left\{\frac{\Pi_{o}+C_{-i}}{\Pi_{b}+w x}, 1\right\} x\right]^{\prime}\right) x \frac{f(w)}{F\left(v_{-i}\right)} d w>0 .
\end{aligned}
$$

Because in the neighborhood of the equilibrium $\partial \delta_{i} / \partial x>0, \partial \delta_{i} / \partial v_{i}>0$, and $\partial \delta_{i} / \partial v_{-i}<0$, where $i \in\{1,2\}$, the right-hand side of (A27) is negative. Because $v_{i}^{\prime}(x)<0$ in equilibrium with strictly decreasing strategies, $\frac{\partial \delta_{1}}{\partial v_{1}} \frac{\partial \delta_{2}}{\partial v_{2}}-\frac{\partial \delta_{1}}{\partial v_{2}} \frac{\partial \delta_{2}}{\partial v_{1}}>0$ at the equilibrium.

Using this lemma, we can prove comparative statics. Consider the derivative of $\delta_{i}\left(x, v_{i}, v_{-i}, \Theta\right)$ with respect to $\theta \in \Theta$ at the equilibrium. Combining the equations for $i \in\{1,2\}$, we obtain:

$$
\left(\frac{\partial \delta_{1}}{\partial v_{1}} \frac{\partial \delta_{2}}{\partial v_{2}}-\frac{\partial \delta_{1}}{\partial v_{2}} \frac{\partial \delta_{2}}{\partial v_{1}}\right) \frac{\partial v_{i}}{\partial \theta}=\frac{\partial \delta_{i}}{\partial v_{-i}} \frac{\partial \delta_{-i}}{\partial \theta}-\frac{\partial \delta_{i}}{\partial \theta} \frac{\partial \delta_{-i}}{\partial v_{-i}}
$$

Lemma 1 implies that the sign of $\partial v_{i} / \partial \theta$ coincides with the sign of the right-hand side of (A28). As shown above, $\frac{\partial \delta_{i}}{\partial v_{-i}}<0$ and $\frac{\partial \delta_{-i}}{\partial v_{-i}}>0$. In addition, because $v_{i}(x)$ is the inverse function of $\bar{X}_{i}(v)$ and $\bar{X}_{i}^{\prime}(v)<0$, the sign of $\partial v_{i}(x) / \partial \theta$ coincides with the sign of $\partial \bar{X}_{i}(v) / \partial \theta$. This can be seen from the full derivative of $\bar{X}_{i}(v)$ with respect to $\theta$ :

$$
\bar{X}_{i}^{\prime}(v) \frac{\partial v_{i}}{\partial \theta}+\frac{\partial \bar{X}_{i}(v)}{\partial \theta}=0
$$

Therefore, a sufficient condition for $\partial \bar{X}_{i}(v) / \partial \theta$ to be positive (negative) is that $\partial \delta_{i} / \partial \theta<0\left(\partial \delta_{i} / \partial \theta>0\right)$ for both $i \in\{1,2\}$.

First, consider $\theta=\beta$ :

$$
\begin{aligned}
\frac{\partial \delta_{i}\left(x, v_{i}, v_{-i}, \Theta\right)}{\partial \beta} & =\mathbb{E}\left[\min \left\{\frac{\Pi_{o}+C_{i}}{\Pi_{b}+w x}, 1\right\}\left(v_{i}-w\right) \mid w \leq \min _{j \in\{1,2\}} v_{j}(x)\right] x-\Delta \frac{F\left(\max _{j \in\{1,2\}} v_{j}(x)\right)}{F\left(v_{i}(x)\right)} \\
& =\frac{1}{\beta} \mathbb{E}\left[\left[\min \left\{\frac{\Pi_{o}+C_{i}}{\Pi_{b}+w x}, 1\right\} x\right]^{\prime}\left(v_{i}(x)-w\right) \mid w \leq \min _{j \in\{1,2\}} v_{j}(x)\right] x>0,
\end{aligned}
$$

where the second equation sign holds by the first-order condition. Hence, $\partial \bar{X}_{i}(v) / \partial \beta<0$. Because $\partial \beta / \partial \mu<$ $0, \partial \beta / \partial \sigma<0$, and $\partial \beta / \partial r>0$, we obtain $\partial \bar{X}_{i} / \partial \mu>0, \partial \bar{X}_{i} / \partial \sigma>0$, and $\partial \bar{X}_{i} / \partial r<0$.

Second, consider $\theta=\Delta$, keeping $\Pi_{b}$ fixed. If $C_{i} \rightarrow \infty$,

$$
\frac{\partial \delta_{i}\left(x, v_{i}, v_{-i}, \Theta\right)}{\partial \Delta}=-\beta \frac{F\left(\max _{j \in\{1,2\}} v_{j}\right)}{F\left(v_{i}\right)}<0
$$


If $C_{i}<\Delta$,

$$
\frac{\partial \delta_{i}\left(x, v_{i}, v_{-i}, \Theta\right)}{\partial \Delta}=-\mathbb{E}\left[\frac{1}{\Pi_{b}+w x}\left(\beta-\frac{\Pi_{b}}{\Pi_{b}+w x}\right)\left(v_{i}-w\right) \mid w \leq \min _{j \in\{1,2\}} v_{j}\right] x-\beta \frac{F\left(\max _{j \in\{1,2\}} v_{j}\right)}{F\left(v_{i}\right)}<0
$$

Hence, $\partial \bar{X}_{i}(v) / \partial \Delta>0$.

Finally, consider $\theta=\Pi_{b}$, keeping $\Delta$ fixed. If $C_{i} \rightarrow \infty, \partial \delta_{i}\left(x, v_{i}, v_{-i}, \Theta\right) / \partial \Pi_{b}=0$. If $C_{i}<\Delta$,

$$
\begin{aligned}
\frac{\partial \delta_{i}\left(x, v_{i}, v_{-i}, \Theta\right)}{\partial \Pi_{b}} & =\mathbb{E}\left[\frac{\left(w x+\Delta-C_{i}\right)\left(\beta\left(\Pi_{b}+w x\right)-\Pi_{b}\right)-w x\left(\Pi_{b}-\Delta+C_{i}\right)}{\left(\Pi_{b}+w x\right)^{3}}\left(v_{i}-w\right) \mid w \leq \min _{j \in\{1,2\}} v_{j}\right] \\
& >\mathbb{E}\left[\frac{2 w^{2} x^{2}+\left(\Delta-C_{i}\right)\left(\Pi_{b}+3 w x\right)}{\left(\Pi_{b}+w x\right)^{3}}\left(v_{i}-w\right) \mid w \leq \min _{j \in\{1,2\}} v_{j}\right]>0
\end{aligned}
$$

where the first inequality follows from $\beta>2$. Hence, $\partial \bar{X}_{i}(v) / \partial \Pi_{b} \leq 0$.

\section{Appendix B Asymmetric Initiation: Numerical Procedure}

For illustrative purposes, consider the case of cash versus stock bidder, $C_{1} \rightarrow \infty, C_{2}=0$. The case of endogenous means of payment is numerically solved in the same fashion, using equations (??). We use substitution of variables to express the first order conditions for the two asymmetrically constrained bidders in terms of $\bar{X}_{1}^{-1}(x), \bar{X}_{2}^{-1}(x)$ for a given initiation threshold $x$. Specifically, let

$$
\begin{aligned}
& x_{1} \equiv \bar{X}_{1}\left(v_{1}\right) \Rightarrow v_{1}=\bar{X}_{1}^{-1}\left(x_{1}\right), \bar{X}_{2}^{-1}\left(\bar{X}_{1}\left(v_{1}\right)\right)=\bar{X}_{2}^{-1}\left(x_{1}\right) \\
& x_{2} \equiv \bar{X}_{2}\left(v_{1}\right) \Rightarrow v_{2}=\bar{X}_{2}^{-1}\left(x_{2}\right), \bar{X}_{1}^{-1}\left(\bar{X}_{2}\left(v_{2}\right)\right)=\bar{X}_{1}^{-1}\left(x_{2}\right) .
\end{aligned}
$$

Then, the system of equations (21), (23) becomes

$$
\begin{aligned}
& x_{1}=\frac{\beta}{\beta-1} \frac{\Delta}{\bar{X}_{1}^{-1}\left(x_{1}\right)-\int_{\underline{v}}^{\bar{X}_{1}^{-1}\left(x_{1}\right)} w \frac{f(w)}{F\left(\bar{X}_{1}^{-1}\left(x_{1}\right)\right)} d w} \frac{F\left(\bar{X}_{2}^{-1}\left(x_{1}\right)\right)}{F\left(\bar{X}_{1}^{-1}\left(x_{1}\right)\right)}, \\
& x_{2} \int_{\underline{v}}^{\bar{X}_{1}^{-1}\left(x_{2}\right)} \frac{\Pi_{o}\left(\Pi_{b}+\frac{\beta}{\beta-1} w x_{2}\right)}{\left(\Pi_{b}+w x_{2}\right)^{2}}\left(\bar{X}_{2}^{-1}\left(x_{2}\right)-w\right) \frac{f(w)}{F\left(\bar{X}_{1}^{-1}\left(x_{2}\right)\right)} d w=\frac{\beta}{\beta-1} \Delta .
\end{aligned}
$$

We have two equations and four different combinations of functions and arguments as unknowns. We consider the interior case $\left(\bar{X}_{i}^{-1}(x) \in(\underline{v}, \bar{v})\right.$ for $\left.i \in\{1,2\}, x \in\left\{x_{1}, x_{2}\right\}\right)$. Assume that both boundaries are equal, $x_{1}=x_{2}=x$, for some $v=\bar{X}_{1}^{-1}(x), w=\bar{X}_{2}^{-1}(x)$. This allows to simplify the system to two non-linear equations and two functions of one argument as unknowns, which can be easily solved with a mathematical package.

Note that the above algorithm does not provide corner solution for $v>\tilde{v}=\bar{X}_{1}^{-1}\left(X_{2}(\bar{v})\right)$. Observe, 
however, that (B2) in this case can be rewritten as

$$
x=\frac{\beta}{\beta-1} \frac{\Delta}{\bar{X}_{1}^{-1}(x)-\int_{\underline{v}}^{\bar{X}_{1}^{-1}(x)} w \frac{f(w)}{F\left(\bar{X}_{1}^{-1}(x)\right)} d w} \frac{1}{F\left(\bar{X}_{1}^{-1}(x)\right)},
$$

and does not depend on $\bar{X}_{2}^{-1}(x)$. As a result, a single non-linear equation with a single unknown is easily solved numerically. Combinations $\left(\bar{X}_{1}^{-1}(x), x\right)$ and $\left(\bar{X}_{2}^{-1}(x), x\right)$ constitute pairs of valuations and equilibrium initiation strategies for the two bidders.

As an example, when bidder valuations are uniformly distributed on $[\underline{v}, \bar{v}]$, in the interior case

$$
\begin{aligned}
& x=\frac{\beta}{\beta-1} \frac{\Delta}{\left(\bar{X}_{1}^{-1}(x)-\underline{v}\right) / 2} \frac{\bar{X}_{2}^{-1}(x)-\underline{v}}{\bar{X}_{1}^{-1}(x)-\underline{v}} \\
& x \int_{\underline{v}}^{\bar{X}_{1}^{-1}(x)} \frac{\Pi_{o}\left(\Pi_{b}+\frac{\beta}{\beta-1} w x\right)}{\left(\Pi_{b}+w x\right)^{2}} \frac{\bar{X}_{2}^{-1}(x)-w}{\bar{X}_{1}^{-1}(x)-w} d w=\frac{\beta}{\beta-1} \Delta .
\end{aligned}
$$

The integral in (B6) has a closed form representation.

\section{References}

[1] Betton, Sandra, B. Espen Eckbo, and Karin S. Thorburn, 2008, Corporate Takeovers, in: B. Espen Eckbo, ed., Handbook of Corporate Finance: Empirical Corporate Finance, Vol.2, Elsevier.

[2] Betton, Sandra, B. Espen Eckbo, and Karin S. Thorburn, 2009, Merger Negotiations and the Toehold Puzzle, Journal of Financial Economics, 91, 158-178.

[3] Berkovitch, Elazar, and M. P. Narayanan, 1990, Competition and the Medium of Exchange in Takeovers, Review of Financial Studies, 3, 153-174.

[4] DeMarzo, Peter M., Ilan Kremer, and Andrzej Skrzypacz, 2005, Bidding with Securities: Auctions and Security Design, American Economic Review, 95, 936-959.

[5] Eckbo, B. Espen, Ronald M. Giammarino, and Robert L. Heinkel, 1990, Asymmetric Information and the Medium of Exchange in Takeovers: Theory and Tests, Review of Financial Studies, 3, 651-675.

[6] Eckbo, B. Espen, and Herwig Langohr, 1989, Information Disclosure, Method of Payment, and Takeover Premiums: Public and Private Tender Offers in France, Journal of Financial Economics, 24, 363-403.

[7] Fishman, Michael J., 1989, Preemptive Bidding and the Role of the Medium of Exchange in Acquisitions, Journal of Finance, 44, 41-57.

[8] Franks, Julian R., Robert S. Harris, and Colin Mayer (1988), Means of Payment in Takeovers: Results for the U.K. and the U.S., in A. Averbach, ed.: Corporate Takeovers, NBER, University of Chicago Press.

[9] Hackbarth, Dirk, and Jianjun Miao, 2011, The Dynamics of Mergers and Acquisitions in Oligopolistic Industries, Journal of Economic Dynamics and Control, 36, 585-609.

[10] Hackbarth, Dirk, and Erwan Morellec, 2008, Stock Returns in Mergers and Acquisitions, Journal of Finance, 63, 1213-1252.

[11] Hansen, Robert G., 1985, Auctions with Contingent Payments, American Economic Review, 75, 862-865.

[12] Hansen, Robert G., 1987, A Theory for the Choice of Exchange Medium in the Market for Corporate Control, Journal of Business, 60, 75-95. 
[13] Harford, Jarrad, 2005, What Drives Merger Waves?, Journal of Financial Economics, 77, 529-560.

[14] Jovanovic, Boyan, and Peter L. Rousseau, 2002, The q-Theory of Mergers, American Economic Review, 92, 198-204.

[15] Lambrecht, Bart M., 2004, The Timing and Terms of Mergers Motivated by Economies of Scale, Journal of Financial Economics, 72, 41-62.

[16] Maksimovic, Vojislav, and Gordon M. Phillips, 2001, The Market for Corporate Assets: Who Engages in Mergers and Asset Sales, and are There Any Gains?, Journal of Finance, 2001, 2020-2065.

[17] Milgrom, Paul R., and Robert J. Weber, 1982, A Theory of Auctions and Competitive Bidding, Econometrica, 50, 1089-1122.

[18] Mitchell, Mark L., and J. Harold Mulherin, The Impact of Industry Shocks on Takeover and Restructuring Activity, Journal of Financial Economics, 41, 193-229.

[19] Morellec, Erwan, and Alexei Zhdanov, 2005, The Dynamics of Mergers and Acquisitions, Journal of Financial Economics, 77, 649-672.

[20] Morellec, Erwan, and Alexei Zhdanov, 2008, Financing and Takeovers, Journal of Financial Economics, $87,556-581$.

[21] Myers, Stewart C., and Nicholas S. Majluf, 1984, Corporate Financing and Investment Decisions when Firms Have Information that Investors Do not Have, Journal of Financial Economics, 13, 187-221.

[22] Rhodes-Kropf, Matthew, and S. Viswanathan, 2000, Corporate Reorganizations and Non-Cash Auctions, Journal of Finance, 55, 1807-1849.

[23] Rhodes-Kropf, Matthew, and S. Viswanathan, 2004, Market Valuation and Merger Waves, Journal of Finance, 59, 2685-2718. 
Table I: Benchmark model parameters

This table reports the benchmark parametrization of the model.

\begin{tabular}{lll}
\hline \hline Variable & Description & Value \\
\hline$r$ & Risk-free rate & 0.05 \\
$\mu$ & Growth rate of target value & 0.01 \\
$\sigma$ & Volatility of growth rate of target value & 0.25 \\
$\Pi_{b}$ & Initial value of bidders & 100 \\
$\Pi_{o}$ & Post-takeover value of the losing bidder & 95 \\
$\Delta$ & Value loss of the losing bidder & 5 \\
$v$ & Lowest value of the acquired target & $110 \%$ \\
$\bar{v}$ & Highest value of the acquired target & $150 \%$ \\
$F(v)$ & Distribution of synergies & Uniform \\
$D(v)$ & Dispersion of synergies* & $11.55 \%$ \\
\hline \hline
\end{tabular}

* Note: Dispersion of synergies for the uniform distribution is $D(v)=$ $\sqrt{(\bar{v}-\underline{v})^{2} / 12}$. 